Type of the Paper (Article, Review, Communication, etc.)

\title{
Developing participatory analytics techniques to inform the prioritization of cycling infrastructure
}

\author{
Oliver Lock ${ }^{1,2^{*}}$, Christopher Pettit ${ }^{1}$ \\ ${ }^{1}$ City Futures Research Centre. Faculty of Built Environment. University of New South Wales. Sydney, Australia. \\ ${ }^{2}$ Expanded Perception and Interaction Centre (EPICentre). Faculty of Art \& Design. University of New South Wales. Sydney, Australia. \\ ${ }^{*}$ Corresponding author
}

Oliver Lock ORCID: https://orcid.org/oooo-0003-4165-1232

Christopher Pettit ORCID: https://orcid.org/oooo-0002-1328-9830

\section{Conflicts of Interest}

The authors declare no conflict of interest.

\section{Acknowledgments}

Research was conducted by Oliver Lock as part of his PhD studies, funded by the UNSW Scientia scholarship scheme.

1 Oliver Lock; o.lock@student.unsw.edu.au*

2 Christopher Pettit 2; c.pettit@unsw.edu.au

* Correspondence: o.lock@student.unsw.edu.au

\begin{abstract}
The planning of bicycle infrastructure across our cities remains is a complex task involving many key stakeholders including the community, who traditionally have had limited involvement in the planning process. This research develops an interactive bicycle prioritisation index tool which includes participatory spatial and textual citizen feedback. The research involves three components. Firstly, a survey of current cyclists in Sydney, their current level of participation, priorities in investment in cycling, and preferred locations for cycling infrastructure. Secondly, it documents the development of an interactive digital bicycle planning tool which is informed through citizen feedback. Thirdly, it evaluates the approach in conversation with potential end-users, including government, planning practitioners, and advocacy group members. The research proposes the combination of multiple passive and active data traces with end-user evaluation to legitimise the citizen co-design of bicycle investment prioritisation initiatives. A case study approach has been taken, focusing on the city of Sydney, Australia. The bicycle planning support system can be used by cities when engaging in cycle prioritisation initiatives, particularly with a focus on integrating citizen feedback and navigating new and complex data landscapes introduced through recent, passively collected big data sets.
\end{abstract}

Key words: active transport, PPGIS, planning support systems, infrastructure prioritisation, bicycle planning, public participation

\section{Introduction}

All aspects of human life in cities rely on efficient and equitable transport. Without it, people cannot access employment, essential services like health and education, goods like fresh food, nor each other to form strong relationships which increase the economic productivity of society, our safety and our wellbeing. However, transport infrastructure is 
a public good - it will not be built without adequate government planning and public funding. As such, good public policy must leverage limited resources to achieve the best outcomes for citizens while balancing competing priorities.

Transport policy must prioritise more than just limited funding - it must face the challenge of allocating fixed amounts of space between cars, public mass transport, and people. Prioritising public mass transport and active transit (cycling and walking) makes people healthier and happier (Oja et al. 2011). Cities that give cars priority over people hurt property values and economic success (J. R. Kenworthy and Laube 1999; J. Kenworthy 2012). However many cities around the world, such as Australian cities, still allocate the majority of transport funding and policy effort to cars (Searle and Legacy 2019), resulting in the widening of freeways and roads. Conversely, there has been little research and development into evidence-based tools to support the planning of bicycle infrastructure. The measurement of 'time savings' in infrastructure evaluation as part of cost-benefit analysis does not accurately reflect many other values of transport benefit:

the use of travel time savings as a 'benefit' does not always apply for public transport, cycling or walking journeys, where the experience of travel, including the potential for work productivity, accessing entertainment, the level of exercise, and the status or attitude to travel may be much more important (Hickman and Dean 2018).

This imbalance in the quantification of modes of transport is changing. Data about movements is collected from a wide range of sources - collection methods can be 'purposeful' or 'active' survey or counting mechanisms or data collection from 'organic' or 'passive' data sources, such as third-party apps and services. Data collection from these apps and services has, in emerging research on surveillance and mobility, been identified as potentially non-transparent about commercial motives - whereby data from individual users is sold on to third parties with disregard to informed consent of how it is used (Alvarez León 2019; Petersen 2019; Zuboff 2019). Recent research on the use of natural language processing for social media listening has also suggested that people would prefer active ways to contribute opinions on transportation than primarily through passive data collection, and this should be seen as a complementary data source (Lock and Pettit 2020).

In cities with low cycling rates, such as this research's context in Australian cities, it is difficult to truly understand cyclist's and potential cyclists desires from limited, opportunistically collected data (Aldred et al. 2017). Further, reliance on such data sources potentially leads under-representation of groups who would cycle more if they had access to increased provision of infrastructure, such as separated bicycle lanes (Aldred et al. 2017). As such, decision-makers may not be able to see the whole picture. Official and available data sources inform policy decisions - if this data is wrong or incomplete, decision-makers will not make good decisions that balance priorities appropriately. It is important to investigate how the transport priorities of cyclists can be better collected and understood through the fusion of available data sources and increasing availability of digital tools. 
This research investigates an approach that builds on previous investigations of public participation geographic information systems (PPGIS; Sieber 2006). These systems and technologies are currently used in research and practice to engage cyclists and collect information to inform cycling infrastructure prioritisation. In the context of Australia, PPGIS have mixed uptake by local councils, who would obtain feedback from citizen on predetermined cycle routes already planner by transport planners. However, such tools do not capture the citizen priority routes, not provide metrics on the likelihood more people will cycle in a particular new piece of bicycle infrastructure is incorporated in the existing cycling network. In is in this context this research endeavours to make a new contribution in the development and evaluation of a participatory planning support system.

The research proposes an approach for collecting data about cyclists' (and potential cyclists') priorities to help inform these decisions through a participatory analytics approach.

The study seeks to answer the following two research questions (RQs).

RQ1 - What are the existing passive and active participation mechanisms for collecting data on cycling behaviour and preferences?

RQ2 - How can these data be integrated within a participatory planning support system to better understand and communicate priorities for existing and potential future cyclists?

These research questions will be examined in the context of the city of Sydney, Australia. The remainder of the paper is structured as follows. First, it will describe the background to the research - in terms of data analysis approaches, data collection and digital approaches to cycling participation. It will then outline the method of three different stages of this research to investigate these questions - a web survey, tool development and interviews. Following this, it will discuss the results, relevance of the findings and future implications on research and practice.

\section{Background}

\section{Data analysis approaches}

The process of data analysis is commonly perceived to be a highly skilled activity that requires training in specific tools, as well as a high level of literacy and numeracy to do well. It can be time-consuming, tedious and mistakes can easily be made. Consequently, the process of data analysis is often excluded from public participation processes. Further, it can be argued that assigning analysis tasks to communities may be an inefficient use of a limited resource (particularly if researchers, experts and practitioners are already trained to take on these tasks; Coghlan and Brydon-Miller, 2014). However, rather than adopting a deficit model (i.e. considering community members to be lack skills or knowledge in particular areas), many researchers are finding ways to build on the wealth of community knowledge in engaging them in accessible analysis opportunities (Coghlan and Brydon- 
Miller 2014). Such avenues have been explored by Filonik et al. (2014, p.7.), who use the term 'participatory data analytics' to describe 'development of interfaces to support collaborative, community-led inquiry into data'. Furthermore, the field of visual analytics specifically explores how visual interactive interfaces can support analytical reasoning (Thomas and Cook 2006). In this context, the purposeful and opportunistic use of data for better city planning should be considered.

\section{Data collection}

In many ways, citizens may be contributing to data analysis processes for city planning indirectly. In Australia - and many parts of the world - application services such as Strava (an application used to record physical activity), TomTom, and mobile phone providers collect user data and re-package it for various urban planning purposes, such as for use by transportation planning authorities. The movements of users are distilled into metrics which help inform infrastructure investment scenarios. A potential issue with this form of participation has been described as a 'big data divide' (Andrejevic 2014). This is characterised by a lack of access to individuals' own passively-collected data, as well as the analytical capabilities to understand how other organisations may be using it and a lack of means to validate the correctness of the assumptions and insights generated by its use (Andrejevic 2014). On the other hand, purposeful data collection, such as national censuses and household travel surveys, is cross-sectional but potentially more likely to be aligned directly to citizens' needs. However, these methods do not capture the same intricate details about the network's use on a day to day basis or in response to certain events. As such, the participatory analytics approach described in this paper involves engaging end-users in interacting with organic (or 'passive') and purposeful (or 'active') data collected in a variety of ways and in designing and evaluating the digital interfaces within a cycling context in the city of Sydney, Australia.

\section{Digital approaches to cycling participation}

As found by Falco and Kleinhans (2018), academic literature has only provided a limited overview of digital participation platforms (DPPs) to date. This is characterised by a few demographic and spatial contexts and does not account for the significant volume of DPPs that have been used and developed in planning practice globally over the past decade. There has been a significant uplift in the technology available to perform digital engagement exercise. The authors highlight 113 active DPPs, which they identify, analyse, and classify within a citizen-government relationship typology. This chapter focuses on DPPs related to cycling.

One term related to DPPs, specifically focusing on geographic data collection, is participatory planning geographic information systems (or PPGIS), which were originally develop and applied in the context of cities 20 years ago to as platform to better connect citizens into the planning process (Carver et al. 2001). These are geographic information systems that enable local knowledge production through the creation of spatial data by 
local and non-government groups. In the context of biycle planning, one popular approach to PPGIS for collecting public opinion is through a 'pinboard' approach. This approach allows users to drop a pin at an explicit location and provide a combination of tags (for example: like/dislike, safe/unsafe, attractive/unattractive) and comments.

One influential example of this for cycling has been Shareabouts (2012), an open-source participatory mapping platform. Shareabouts was developed from work by OpenPlans and the Department of Transportation in New York City. The project enabled thousands crowdsourced ideas to be collected on the location of new stations for a new, large-scale bike share system in the city. Many cycling participation applications have used Shareabouts' open-source technology, or similar. Crowdspot (2012) worked with the City of Melbourne in developing their Bicycle Plan for 2016 to 2020. Rather than bike share locations, this system collected ideas, issues, and 'likes'. Since then, the same organisation has also adapted this map to assess the safety of the network at a greater Metropolitan scale.

Bikemaps.org is another PPGIS developed specifically for users to report near misses, hazards, and thefts. Insights derived from the developers of the platform indicated that crowdsourced collision data can complement, as well as fill in the gaps of, existing official reports. It also found that crowdsourced reporting of near-miss collisions may be influenced by user perceptions of risk (Branion-Calles, Nelson, and Winters 2017; Nelson et al. 2015). Other platforms, such as Maptionnaire, developed in Helsinki, are similar to Shareabouts but engage users in more detailed survey collection mechanisms, allowing users to navigate some descriptive spatial data layers while making comments. An example of Maptionnaire's application was in Spring 2017, when Caltrans (Californian Department of Transportation) conducted an online survey using Maptionnaire. This survey collected public opinion on needs, issues and recommendations for the Bay Area, San Francisco. Approximately 5000 individuals visited the interactive tool, playing a total of approximately 20,000 recommendations on the map - also later informing that region's bicycle plan.

In terms of mapping passively collected data, companies such as Uber are publicly releasing data as part of their 'city mobility campaign' to show their bike volumes in the city (Uber 2020). This is intended to show where their system of shared bikes and scooters are used most to help inform cities' decisions about where infrastructure opportunities exist, advocating a better network for their delivery partners. There are also research-led dashboards that provide transparent mechanisms to understand crowd-sourced, voluntarily contributed cycle behaviour data, for example the Riderlog dashboard for Australian cities (Pettit, Lieske, and Leao 2016).

Decoupled from active participatory input, but available to the public online, digital planning tools, also known as Planning Support System (PSS) have typically facilitated indirect citizen involvement through the use of survey or movement data. The Impacts of Cycling Tool (ICT) is an open-source PSS with a simple web interface. The PSS uses travel 
survey data to model scenarios of cycling uptake among different segments of the population; including the impacts this would have on greenhouse gas emissions and health (Woodcock et al. 2018). In a similar vein, the Propensity to Cycle Tool (Lovelace et al. 2017) is another example of PSS which incorporate a web interface for users to understand current cycling use and areas with the most potential to grow under different scenarios. As well as potential to cycle, prioritisation indices have also been developed, such as the work of Larsen et al. (2013) for Montreal, Canada. The authors produced an area-based prioritisation index for cycling prioritisation based on four variables - current cycling, cycling potential, injuries and locations suggested by current cyclists.

The earlier examples of PPGIS generally do not provide a clear pathway for how and where this citizen data is transformed into outcomes of a later analytical exercise. In addition to this, when participants provide feedback, they are exposed to limited contextual data which may be useful in assisting them in making an informed comment. On the other hand, the PSS described after this generally do not integrated direct citizen feedback. Rather, these tools rely on existing survey data, passive data, and network characteristics. As well as this, many of the available PPGIS or PSS tools, focus on one particular aspect of the network, participating in one type of cycling infrastructure or one type of cycling incident (e.g., safety).

As such, this research examines a potential digital intervention that combines both active and passive citizen data in a singular interface. This interface is intended to be used by practitioners as a planning support system and by citizens as a participatory tool to view other citizens' voices and explore the effect of alternate investment priorities on the network.

\section{Method}

The method for this case study is outlined by the workflow described in Error! Reference source not found.. The case study is designed to investigate the active and passive data traces that are currently used by cyclists and those potentially interested in cycling. These are then combined into a technical tool. This is then shown to experts and those interested in giving a more detailed input. Conceptually, this process then reiterates until multiple aspects (active - long, active - short and passive) participation are achieved. As such, several participation outlets are explored to design the final tool and create local planning decisions.

This research uses a mixture of methods to allow a combination of numerical measurements and in-depth exploration. The first RQ1, relating to existing passive and active participation mechanisms, and priorities for existing and potential cyclists in Sydney. In exploring this, both quantitative insights to rank and order these - as well as qualitative insights to explore more overarching themes and issues. As such, a survey instrument was used to collect this data. In order to understand RQ2, and whether 
participation inputs have been used in a meaningful way, more detailed qualitative feedback was required. This was obtained through more in-depth, one-on-one interviews.

Each stage of the research process analyses the previous stage - the digital tool analyses the participant input, and the interviews analyse the digital tool. Following this - the interviews and overall research are analysed.

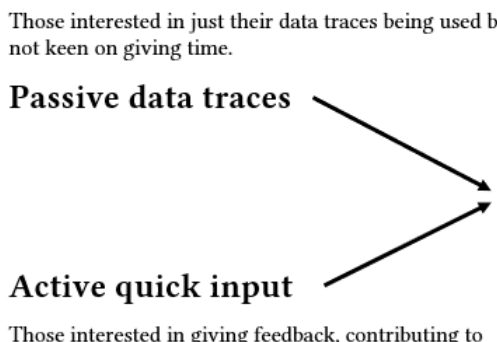
process, with little time.

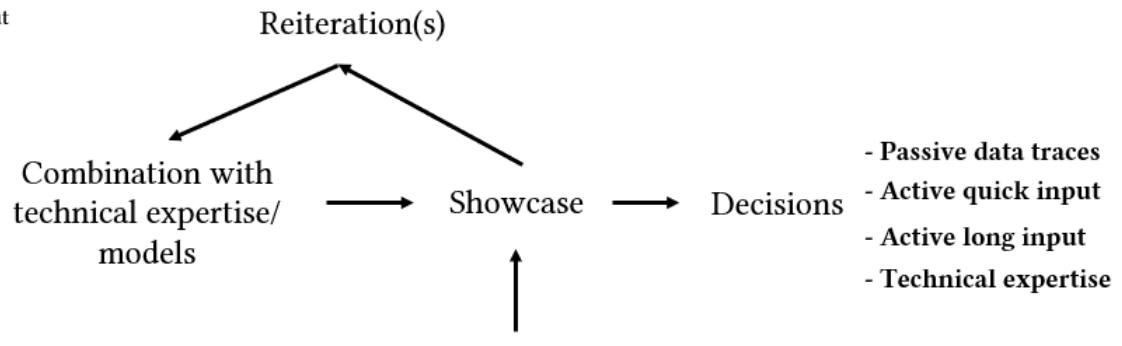

Active long input

Those interested in giving feedback, contributing to process willing to give more time

Figure 1. Workflow of case study

\section{RQ1 - Existing passive and active participation mechanisms and priorities}

The first stage of this study was to conduct a web survey to capture elements which may influence participation in cycle planning in Sydney. This survey was created using the ArcGIS Online Survey123 platform, which allows spatial data to be captured alongside traditional survey questions. A snowball sampling method was used - the researcher sent the survey link to other researchers, transport planning practitioners, cycling advocacy groups, and local and state government workers to distribute to potential participants. The survey began on May 11 th 2020 and finished on June 14 ${ }^{\text {th }}$, 2020, when a sample of 280 was achieved. The first 250 respondents participated within the first two weeks. The full survey can be found in Appendix 1. Initial background questions of survey participants included the following.

- Cycling previous experience, trip purposes, trip frequency, and physical and navigational confidence.

- General engagement in cycle planning (through apps, surveys, meetings) in both active and passive terms.

- Satisfaction with current network and participation mechanisms.

- Preferred engagement format (passive or active).

- Observations of changes to cycling behaviour as a result of COVID-19 (expanded separately to this chapter; see Anonymous, 2020).

Further to these background questions, a participation exercise was also embedded in the survey. This involved two components. Firstly, there was a prioritisation exercise, in which where participants ranked the importance of the following factors:

1) Building more separated cycleways (off-road and away from traffic) 
2) Creating a continuous network that doesn't stop and start

3) Designing safer environments in areas where crashes and collisions have occurred

4) Building and upgrading infrastructure where the most people cycle

5) Building and upgrading infrastructure to specifically support commuter cyclists

6) Building infrastructure where the gradient or slope is easy to ride

7) Building infrastructure in critical locations that will encourage new people to ride bicycles

8) Building infrastructure close to train stations

This was assessed using a Likert scale for each criterion, as well as a question asking for the single most important factor to focus on. The second component of the participation exercise was to ask participants to draw their top cycling improvement for Sydney. Here, participants were asked to draw one specific shape with some accompanying text (see Figure 2). The only restrictions was that only one drawing was permitted - part of the research was to analyse how people responded to this and the various forms by which participants commented.

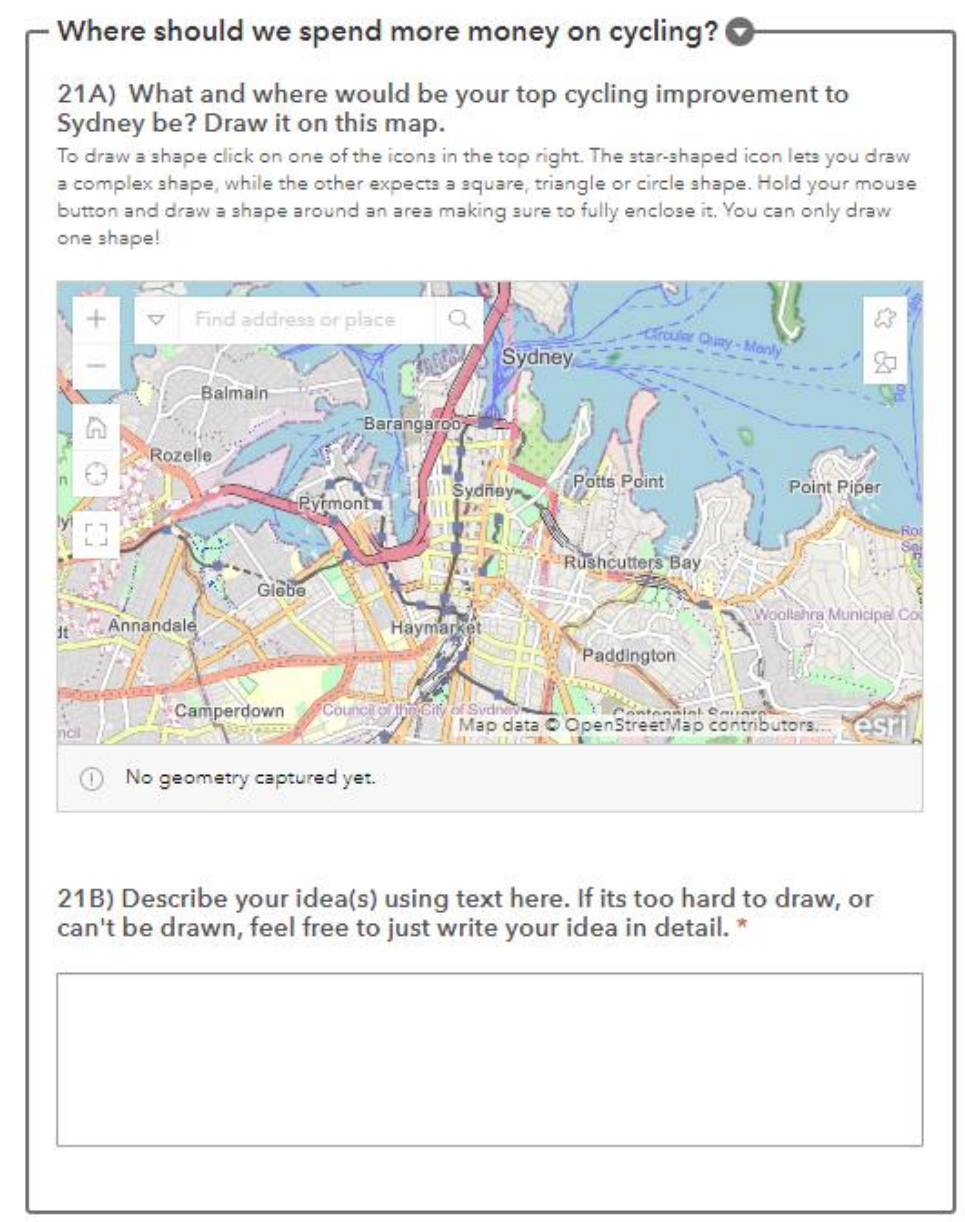

Figure 2 Question asking participants to draw their improvement 


\section{RQ2 - Design and evaluation of digital tools to consolidate participation inputs}

\section{Design}

\section{Spatial collation}

The second stage of this work fed the prioritisation and spatial results from the survey into a prioritisation index (PI) for cycling investments, expanding on the prioritisation elements developed by Larsen et al. (2013). The results were made into participative multicriteria GIS analysis (Milakis and Athanasopoulos 2014). A full description of these data sources can be found in Appendix 2. An image summarising these layers can be found in Figure 3.

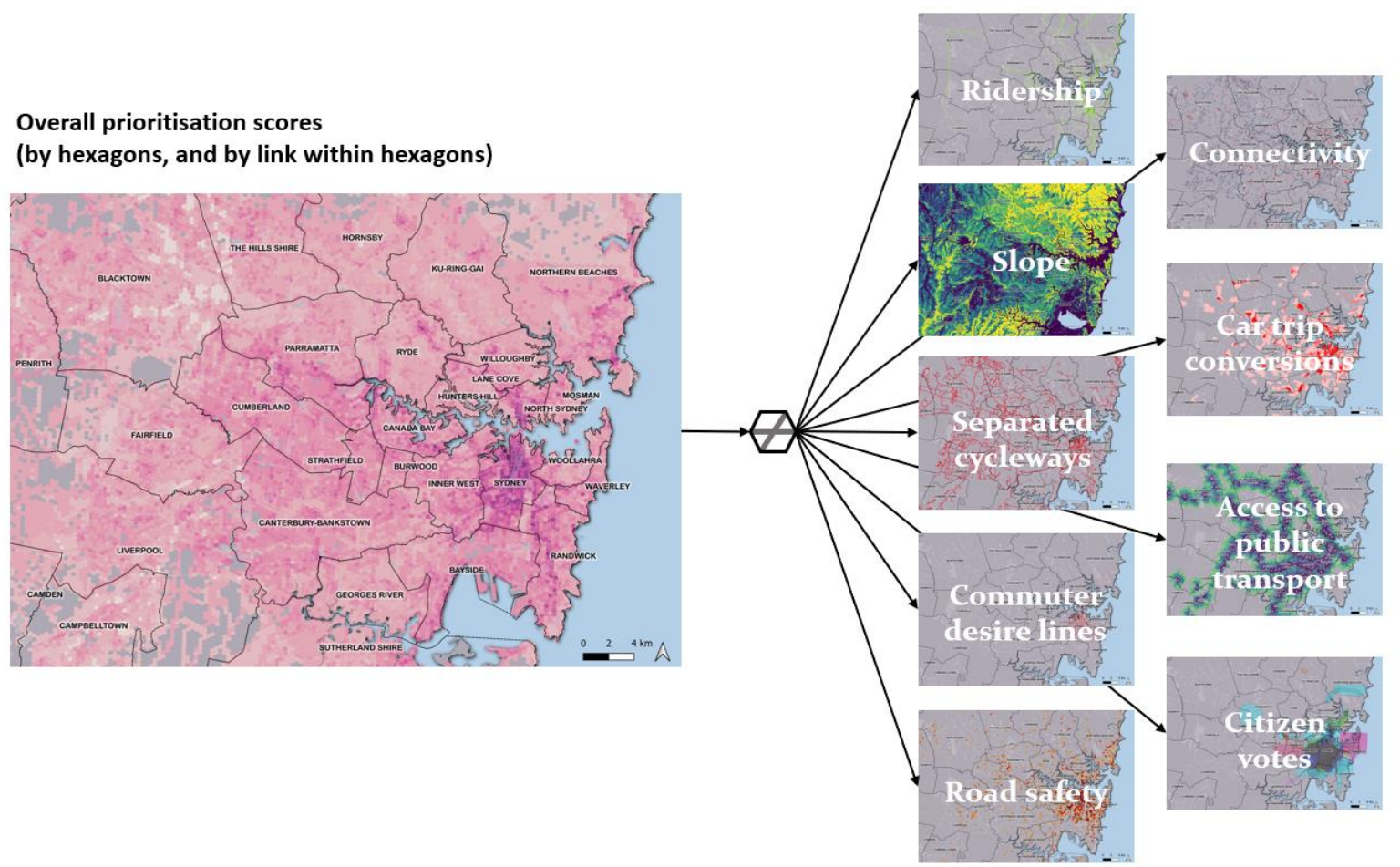

Figure 3. The nine criteria used in participatory prioritisation index

The criteria included the following:

- $\quad$ Priority should be given to areas with limited off-street cycleways.

- Priority should be given to areas that connect the existing network of off-street cycleways.

- Priority should be given to improving the safety of areas where cyclists have crashed.

- Priority should be given to areas where the highest volumes of cyclists use the network

- $\quad$ Priority should be given to corridors that are currently used for commuting purposes.

- Priority should be given to areas within a 10-minute cycle of a train station.

- Priority should be given to areas with a cyclable gradient.

- Priority should be given to areas which will potentially convert short car trips to bike trips.

- $\quad$ Priority should be given to areas where citizens voted or drew ideas for improvements. 
Following the creation of these nine spatial layers, the layers were collated into hexagonal units for the city of Sydney. Each hexagonal unit received a score of 0, 1, or 2, depending on how well they fit the above criteria.

\section{Dashboard development}

An interactive tool was developed to communicate the results of the participatory prioritisation index. This is described in Figure 4. The tool was developed using Bokeh (bokeh.org), a Python visualisation library.

The tool allows users to do the following:

- Select individual councils and view a heatmap of prioritisation in the area.

- Toggle each prioritisation criteria to be 'more important' or 'less important'.

- Investigate which road areas score most highly on a customised prioritisation index.

- Investigate the impact of citizen votes on prioritisation index.

- Investigate potential costing scenarios.

- View scorecards of how particular hexagonal units perform on the index.

- View details on the metric calculations.

One of the unique features of this tool was the ability to view the most relevant citizen comments for each hexagon. This was done by selecting the comment relating to the participant-drawn shape that had the highest proportion of its total area fitting within the hexagon. As such, a prioritisation process was also embedded in comments, allowing the most relevant comments about specific areas to be shown in those areas, and more general comments to be shown in all others around them.
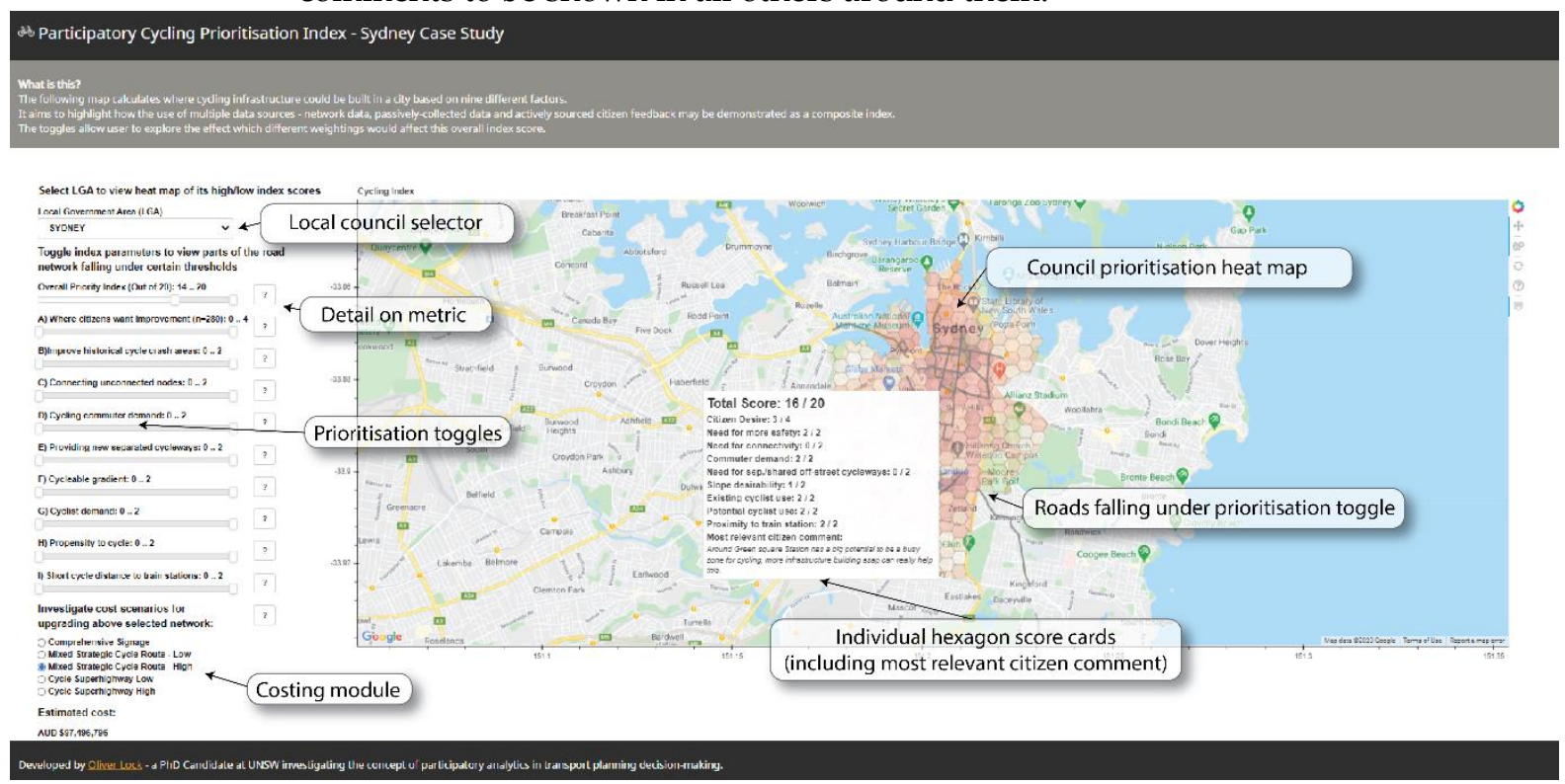

Figure 4. Screenshot of tool with labels of key features 


\section{Evaluation}

\section{Semi-structured interviews}

The third component of this research involved semi-structured interviews giving feedback on the first component (survey) and second component (tool) used in this study. Theoretically, this is to understand the lengthy, deliberative input that could occur at the later ends of this process to inform reiterations of the participation process until a satisfactory process is achieved. In a practical sense, this also allowed an understanding of whether end-users considered the results of the survey to be useful, which aspects were surprising, and their thoughts on extensions and potential applications of the interactive tool.

\section{Interview sampling}

Invitations were sent to approximately 20 of the survey respondents and an additional ten people who were actively engaged in cycle planning or public participation exercises in Australia. A sample of professionals with local, state, and federal government experience in transport; private consulting experience in transport; and experience in digital public participation technology roll-out were interviewed. As well as this, there were individuals with experience in cycle advocacy, the organisation of group and social rides, and participation in local community and public hearing events. Several participants had significant amounts of anecdotal evidence of successful and failed cycling participation initiatives in the city. It is worth noting that many participants had years of experience with various combinations of these areas, so describing them as 'one category' would not do them justice. In total, 15 interviews summarised this knowledge base and provided a detailed database of thoughts on the survey and tool.

\section{Interview structure}

The interviews were held during a period of restricted public movement in Sydney, Australia, due to COVID-19 pandemic. As such, face-to-face research was not possible; one-on-one interviews were conducted over video calls (Microsoft Teams). The interviews were semi-structured and lasted between 45 and 60 minutes.

Firstly, participants described their background, what interested them in cycling, their work experience related to the study, and any other interesting personal anecdotes related to the study. Secondly, participants were shown a series of slides describing participatory analytics, passive data, and actively collected data. Following this, they were shown survey results and asked questions about their thoughts on particular elements, as well as the open-ended question, 'What did you find interesting about this survey?' Participants then watched a 10-minute video describing the full functionality of the tool (a video is also provided to complement this research in Appendix 5). Following this, an open discussion was held with the following prompts: 
- What did you think about the tool or process so far?

- What do you think is the advantage of using this tool or process, over it not being used?

- What improvements do you think could be made to the tool or process?

- What additional data could be used in this tool or process?

- Do you think the data used in this tool or process represents all cyclists?

- Do you think you could use this tool or process in your work? How?

Following the collection of interview responses, key quotes were documented and arranged into themes where they were notable or created patterns among the responses. These themes and quotes are presented in results section.

\section{Results}

This section describes the results of the initial web survey $(n=280)$ and the longer one-onone interviews $(\mathrm{n}=15)$. The full survey results can be found in Appendix 3.

\section{Survey results}

\section{Participant backgrounds}

A total of 280 responses were collected in the survey period between May $11^{\text {th }}$ and June $14^{\text {th }}, 2020$. The majority of responses occurred within the first week of the survey becoming available. The majority of respondents were aged 25-54, in age ranges 35-44 (30\%), 45-54 (25\%) and 25-34 (24\%) respectively. Participants were skewed towards male $(65 \%)$ in terms of gender. The majority of participants were full-time employed (74\%). In terms of education, a high proportion of the sample had tertiary education at bachelor's level or above $-24 \%$ had at least an undergraduate degree and a further $61 \%$ had more specialised education beyond that (e.g., graduate certificate, master's, PhD). The geographic spread of survey participants can be found in

Figure 5, covering many areas of inner Sydney. 


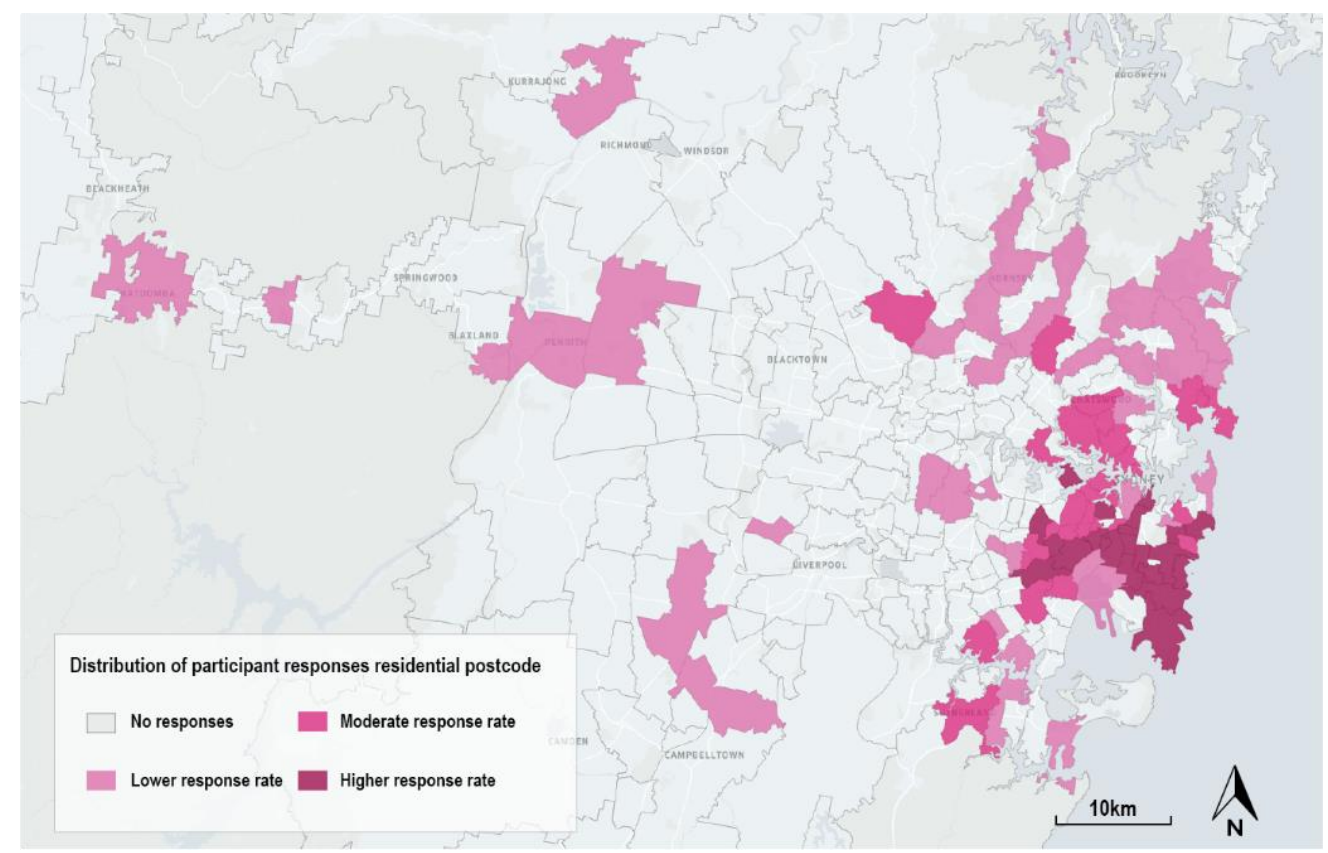
graphic spread of survey participants

Figure 5 Geo- 


\section{Cycling habits}

The main travel purposes by bicycle for participants were for fun and enjoyment $(88 \%)$, for exercise $(80 \%)$, and commuting to and from work $(76 \%)$. The main frequency of cycling was every day or close to every day (36\%), or at least a few times a week (36\%). A total of $78 \%$ of respondents rated themselves as 'confident' or 'very confident' physically riding a bicycle, but only $60 \%$ were confident navigating with a bicycle.

\section{Engagement and satisfaction with cycle planning in Sydney}

One of the key questions of this exercise was around engagement in bicycle infrastructure planning. The main forms of engagement in cycle planning were as follows:

- Participating in the Australian Census (64\%)

- Giving feedback to a local council (55\%)

- Posting on social media (55\%)

- Giving feedback to a state government body (31\%)

- Attending advocacy group meetings and events (20\%)

When asked the proportion of rides that they logged using applications (such as Strava), there was an interesting split between almost every ride to all rides (30\%) being logged and no rides being logged (33\%). Furthermore, for rides which were logged, these were mostly recreational $(20 \%)$, or a mix of recreational and commuting $(32 \%)$.

In terms of satisfaction with existing participation mechanisms, participants were generally not satisfied $(42.5 \%)$ or very unsatisfied $(11.79 \%)$ with mechanisms that were in place. A large number were also neutral (36\%). Participants preferred the engagement format to be active participation. In terms of desired participation, the largest proportion wanted to participate 'actively with no time' (55\%) - these participants wanted very quick ways to contribute to improvements to the network. As well as this, $31 \%$ of participants were willing to give up longer periods for active engagement. Interestingly, less than $1 \%$ wanted nothing to do with influencing the network. Furthermore, $13 \%$ of participants wanted their passive data to be primarily used as their preferred form of participation. On average, participants rated Sydney's cycling network 3.8 out of 10 when prompted. Notably, only six out of the 280 respondents gave the network a score of eight or above.

\section{Investment prioritisation}

When asked, 'to you personally, how important are the following factors in improving the cycle network in Sydney?' participants responded as shown in 
Figure 6. The most important factors were building a continuous network, increasing the number of separated cycleways, and safety. The least important were gradient and infrastructure close the train stations. This was also consistent with naming the number one priority, where approximately $40 \%$ thought separated cycleways were most important, $40 \%$ chose continuous network, and less than $1 \%$ thought that infrastructure close to train stations was most important.

Other important factors discussed by participants were the following:

- More education, training, and marketing programs across all modes (vehicles, bicycles, pedestrians) to create positive behaviours, increase safety, and reduce aggression on roads and cycleways

- Reducing the severity of helmet laws to encourage more cycling trips or participation

- Increased legal enforcement of rules which endanger cyclists

- Additional infrastructure that allows children to ride to school

- $\quad$ Reducing the speed of vehicles in areas with pedestrians and cyclists

- Increasing the width available for cyclists on roads, shared footpaths and shared cycleways

- Higher support for e-bikes to encourage a more diverse cyclist pool

- Higher volume of bike lockers, storage facilities, end-of-trip facilities, and carrying facilities

- Re-designing road signals ('green time') and signage to better support seamless cycling journeys.

Additional information on the top-voted prioritisation factors and key quotes from the other important factors can be found in Appendix 4. 


\section{Average score (1-5) in response to: "How important are the following factors, to you personally, in im- proving the cycle network in Sydney?"}

5 - Very important

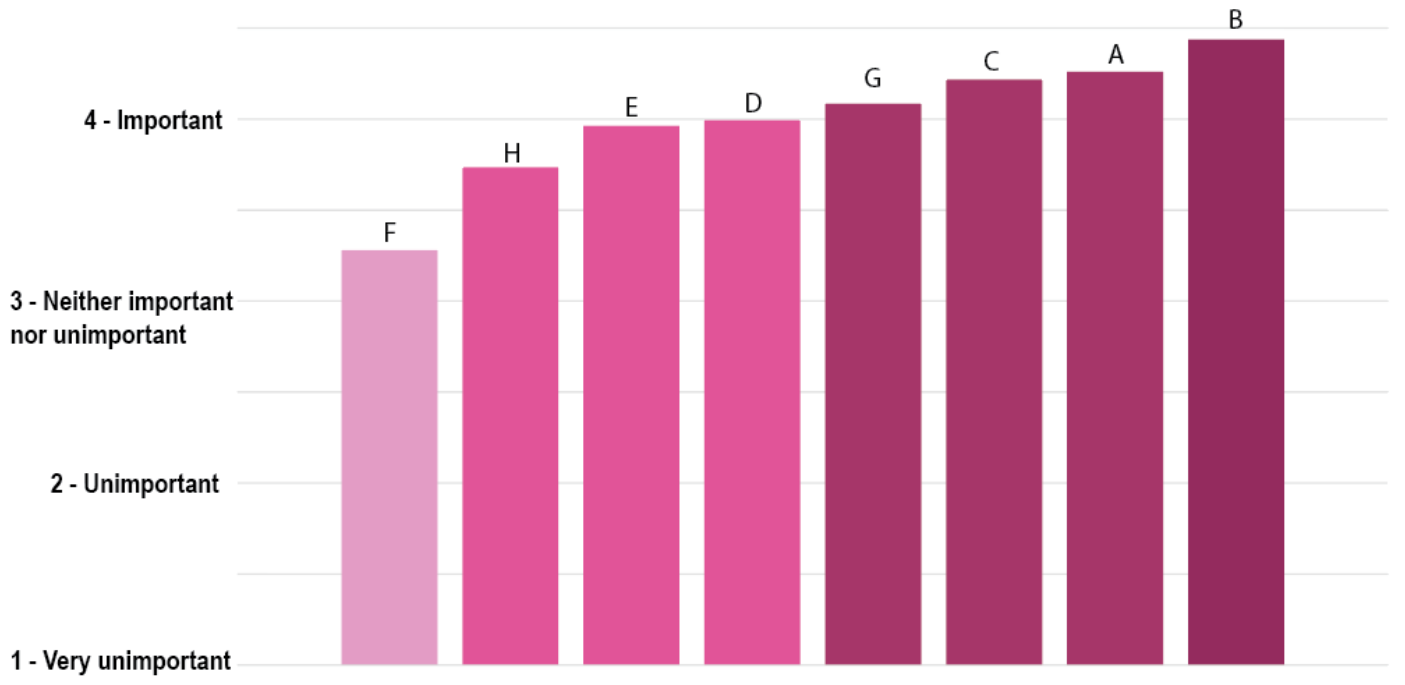

Figure 6

Prioritisation responses assessed with a Likert scale

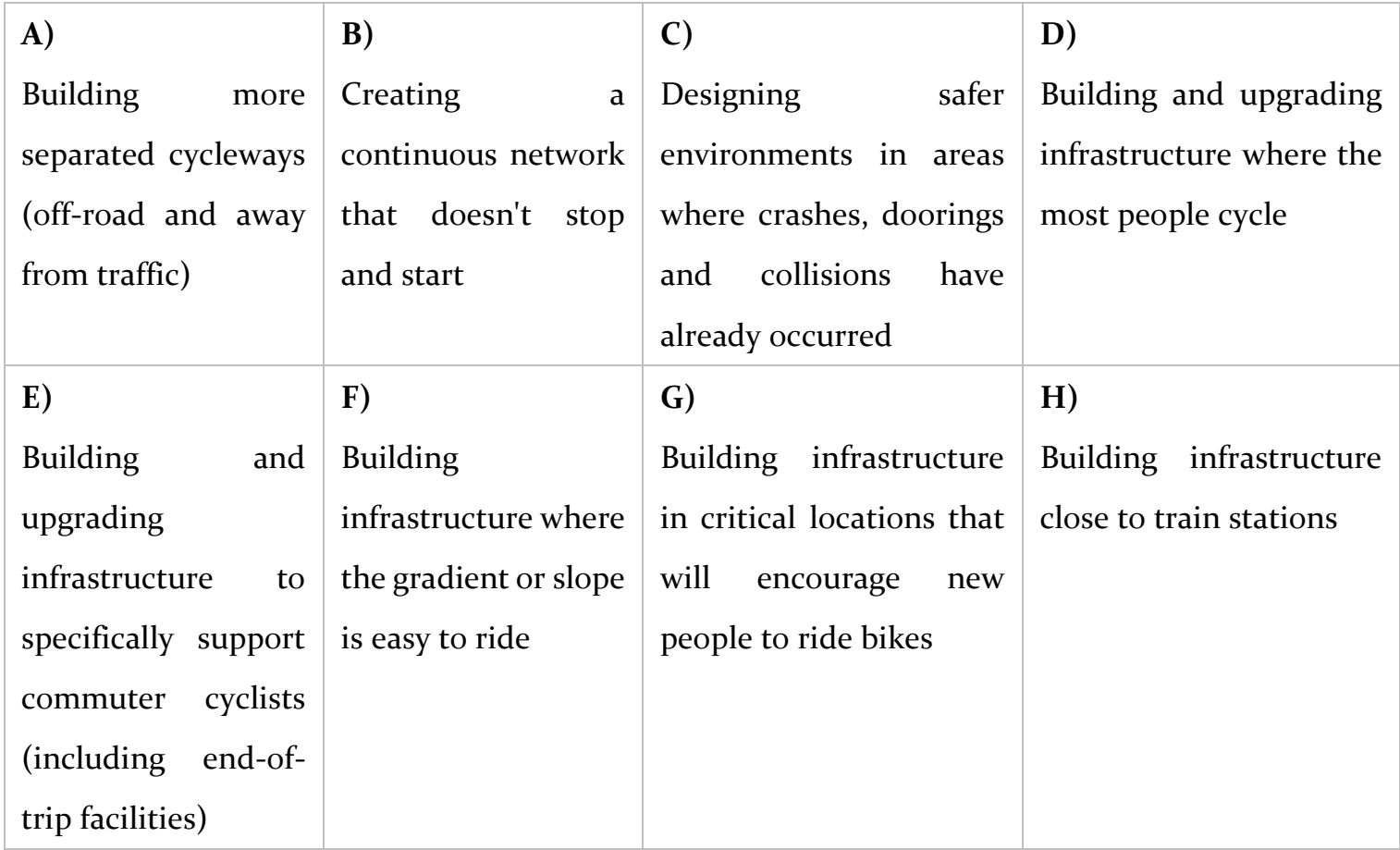

\section{Participant comments}

As well as rating priorities, participants could draw one spatial shape on a map, representing their top idea for cycling investment in Sydney. There was a median distance 
of $3.8 \mathrm{~km}$ between a respondent's postcode and the centre point at which they commented. As there was a vast range of scales at which participants drew their response, filtering by area was found to be a useful way to identify areas and types of comment that were being made. Figure 7 demonstrates the top 200 comments covering the smallest area, which allowed key corridors to be highlighted. Figure 8 shows a heatmap of the comments, summed into individual hexagonal units across the city (showing five or more comments only). Figure 9 shows the results of integrating these comments into the composite index. 


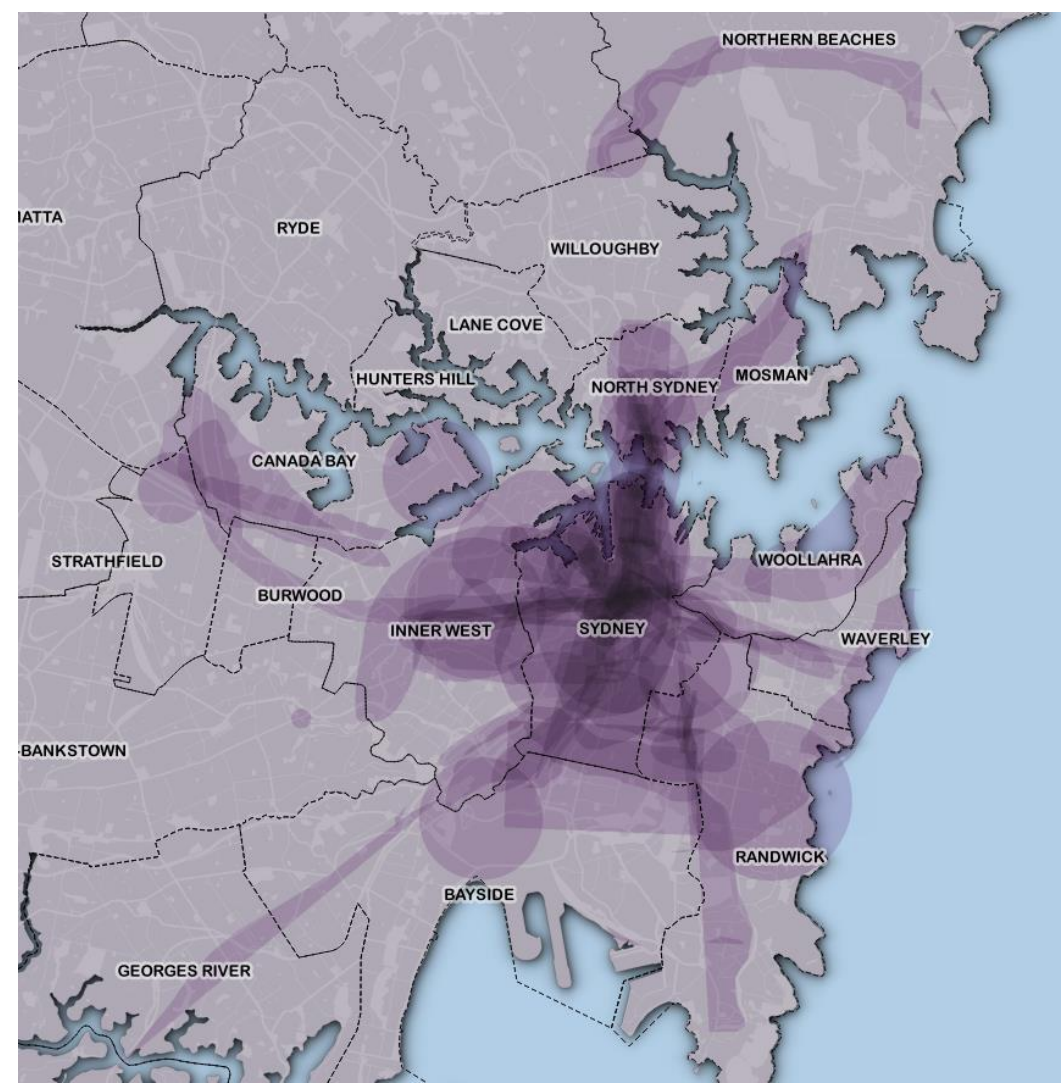

Figure 7 Map demonstrating top 200 smallest comments overlaid on top of each other, revealing key corridors and areas desired by citizens.

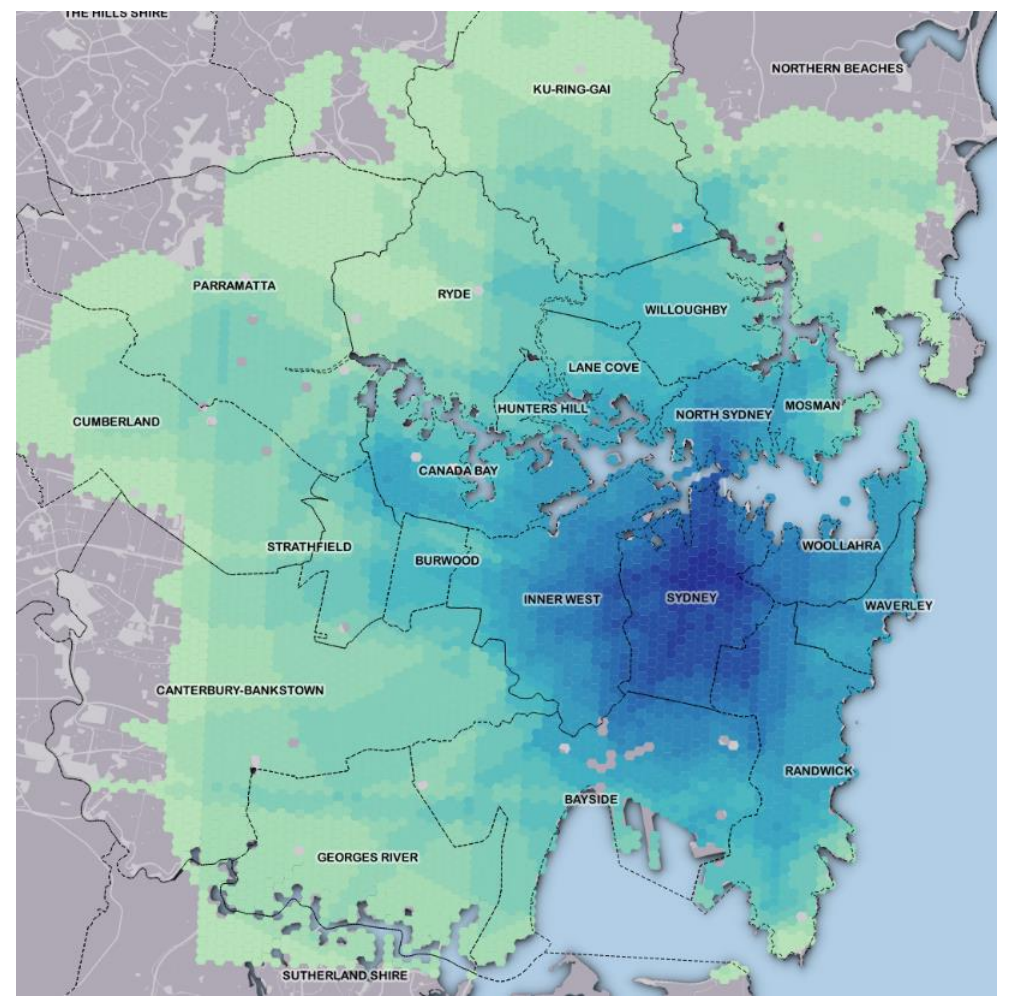

Figure 8 Citizen comments assigned to hexagonal grids (shown, five or more comments covering each cell). Blue indicates a higher number of comments. 


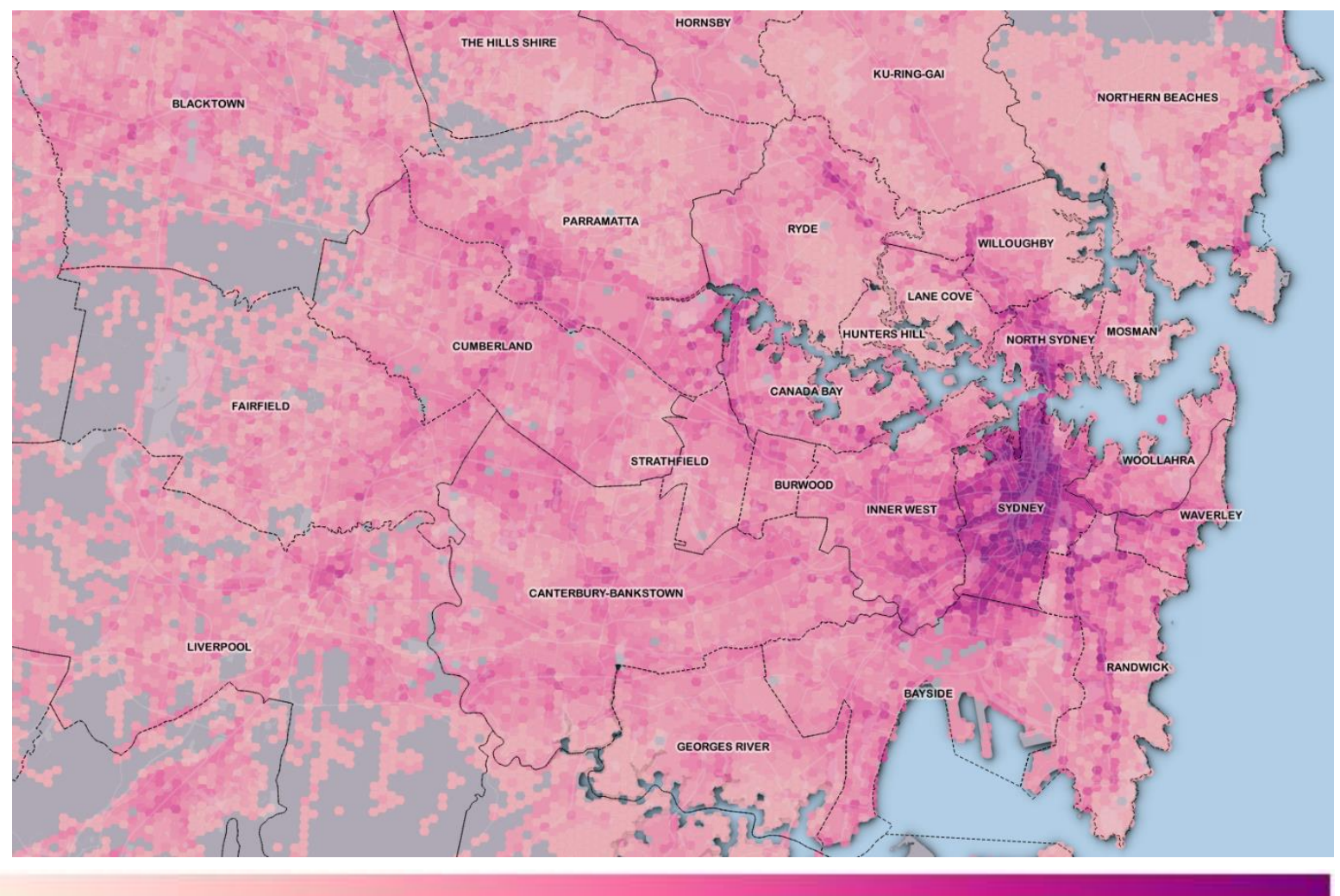

Figure 9 Prioritisation results - combined prioritisation layers, including citizen votes, in one spatial layer. Dark purple indicates highest prioritisation.

\section{Interview results}

After showing the results of the survey and interactive tool to practitioners, the following key feedback themes were identified.

\section{Who would benefit most from using this tool?}

Overwhelmingly, the majority of interviewees responded that local governments were the main user group that would benefit from using this tool and process. One participant summarised this by stating, 'in a polycentric city with lots of councils, with varying degrees to fund infrastructure, and varying capabilities to identify transport needs [in local government], tools like this are important'. Another stated, 'a lot of bureaucracies could tap into this; rather than tap into discrete analysis on a case on case for independent studies'. Another stated that it is an: Impressive and useful tool for councils. Often councils do not have an embedded cycling team. It is a good education tool for those who are not across the cycling network or issues. For those who are not working in cycling, it may be quite illuminating.

Beyond local governments, some other participants said the tool would assist with their transport planning work. For example, one participant stated the following: 
As a transport planner, I could use this tool if I was looking at a study area I wasn't familiar with. I could use it for initial intel to inform my analysis. If I was to do a bike plan for Camden council, I could see what the community has said, see the crashes and so on and how they are influencing the network.

From an advocacy perspective, one participant stated that they 'would like to see the proposed network alongside this so we can comment on it and use it as an evidence base for advocacy'. Another participant saw it as a good tool for advocacy within government, identifying it as a tool to 'negotiate with other road users, advocacy groups, project teams, or groups within government'. In a similar vein, one participant stated, 'Great tool for promoting cycling within government, when meeting with car, freight, rail and heavy infrastructure gives cycling a quantitative evidence base'. Another participant highlighted that there were 'no consistent approaches' to merging participation with analytics work, and that 'high-level government want to see consistency'.

\section{What current features do you like about the tool?}

Several participants stated that they enjoyed seeing everything in the same interface. One stated, 'Love that you have combined lots of different things in one place'. Another stated that it was 'awesome to be able to put everything together like that'. One participant had 'never before seen' so many data sources in one cycling tool.

Some participants stated that it was easy to understand. For example, one participant said, 'If you are Joe Blogs, you would understand it'. Another stated, 'It can be easily explained to anyone, you don't need to be X, Y, Z. Very digestible and good communication'.

Participants also liked the feature that allowed the user to see priorities by individual councils, rather than the prioritisation of the whole network. One participant summarised this as 'we need to stop concentrating so heavily on the CBD [central business district] - there are many work centres, strategic centres, satellite office spaces'.

Another positively highlighted feature was the comment matching system, which provides the most relevant comment for each cell alongside the score. One participant described this as 'a really effective way to combine qualitative and quantitative information'.

\section{What can be added to the tool?}

Some participants suggested including benchmarks of other cities or strategic visions. One participant wanted to know how each cell compared to 'best practice around the world, in cities such as Auckland, San Francisco and London'. Another would like to have seen integration of where the councils or government want the city to be in terms of strategic objectives, but also including proposed projects and how these match the participatory prioritisation work.

Another key suggestion articulated was to enable citizens to see the full array of comments relevant to the area, in order of their priority. This could include the ability to up-vote or add comments after the survey after seeing the data and what participants had commented. Many of the interviewees saw the viewing of other 
citizen's comments as a key beneficial factor of this tool - 'Would people be more motivated to participate if they see someone else, or many other people, are interested in the same issue?'.

In order to improve the tool, several participants suggested adding wider economic benefits, such as congestion reduction, air pollution reduction, and population health improvements into the costing module. Many interviewees also mentioned school drop-offs and considering additional prioritisation criteria that account for encouraging children to cycle to school. As well as this, many considered access to schools as more important than some included criteria several participants considered access to stations less important than schools.

Additional limitations included by several participants were that although there is a 'propensity to cycle' metric, the survey and tool do not capture all would-be cyclists. Several highlighted the need to deliberately find and seek opinions of those who do not and will never cycle, as well as those who would consider cycling.

\section{Other insights into participation}

Several participants explicitly showed their agreement with the concept of the participatory analytics exercise, one stating that 'the analysis has even more legitimacy because it has been through a participatory process'. Some were critical of existing participation mechanisms, one stating that 'a lot of people are not aware of things until once they start digging holes in the ground'.

One participant responded that it is 'a lot of work to build a successful cycling participation exercise - partnership is needed amongst government agencies, advocacy, or user groups and other parties such as UberEATS [who can send internal messages to delivery partners]'.

A respondent also stated that 'government adoption is a barrier to participation exercises. These digital approaches are still quite novel and challenge the role of the expert. Experts are better at solutions; however, the community is much better at identifying problems'. One participant suggested using virtual reality headsets, saying that many more non-cyclists engaged when using this participation mechanism than would engage otherwise. Another participant noted the effectiveness of the 'Shared Spaces' web map in New South Wales, which allowed them to see other participant comments. As a consultant, this participant could download the web map as a data set to use in their own transport planning work. 


\section{Discussion}

This research investigated two key questions. Firstly, what are the existing passive and active participation mechanisms and priorities for cyclists and potential cyclists in Sydney? Secondly, how can digital tools that consolidate these participation inputs in a meaningful way to both citizens and practitioners be designed and evaluated? There were three stages to the research: an initial survey with 280 respondents, the creation of a prioritisation index and a tool integrating the responses, and feedback through 15 in-depth interviews about the previous two stages.

The novel contributions of this work can be seen as an extension of previous works done in PPGIS and PSS introduced in the initial sections of this paper - including a range of passive and active data sources in a singular interface that have been given additional contextual information from survey data and in-depth follow-up interviews. It also provides applied research with specific, real-world generated information highlighting key desires, corridors from citizens as well as from the multi-criteria heat map for the specific geographic area of Sydney, Australia.

In answering the first aspect of the research question, it was found that the process was success in enabling participants to identify key areas for improvement in the city. These participants identified very clear priorities of off-street and separated cycleways, as well as creating a continuous network. In general, the preference for separated cycleways related strongly to research identified in the initial review (Aldred et al. 2017). Participants also articulated strong preferences for additional considerations of promoting cycling among younger, school-aged populations rather than more 'strategic' objectives such as access to train stations. A clear preference for active participation mechanisms (86\%) was articulated, as opposed to a reliance on existing data available and passive data. Though many of the survey participants took part in the Census and other participation mechanisms, participation was surprisingly low across many of the mechanisms which did not match the citizen stated preferences for active engagement. In particular, given the reliance on official data sources, such as Census and travel surveys, on calibrating the existing body of research on cycling PSS, it was surprising to find that only $64 \%$ of participants stated that they responded to this. This has implications on how this data is used, as well as on the importance on a data fusion exercise as performed in this research.

Given the preference for active participation shown by participants, it was unsurprising that the results revealed a general dissatisfaction with existing participation mechanisms - highlighting that there is a desire for more active processes to be employed by practitioners. In terms of the forms of passive data being used, such as logging rides through mobile applications, just over one third of the sample population did not log their rides at all. Those that did log their rides showed a skew toward only for recreational purposes. This presents further challenges for the use of passive data, and again, highlights the need for a mixture of data sources to be used. 
In answering the second aspect of the research question, it was found that the bicycle PSS developed was successful in consolidating participation inputs in a meaningful way to citizens and practitioners. This was evidenced through several factors. Firstly, it was found that drawing explicit spatial shapes (rather than points on a map) was an effective way to highlight key suggestions which fed into a comment-weighting system in the prioritisation index. This allowed strong visuals as to the locations of the comments, as well as assigning relevant comments to particular hexagonal cells to assist with diagnosis of issues highlighted through the index.

Secondly, the prioritisation index was well understood by interview participants and seen as useful - particularly among local government users and for both internal and external advocacy. Through interviews, participants also, again, suggested features such as adding in access to schools, adding in the ability to vote again after the index has been formulated, and measuring against international best practice as well as strategic, government-led benchmarks.

The simple combination of multiple data and analytical layers, including the framing of active and passive participation, was seen by some participants as an important step in increasing the legitimacy of data-driven engagement exercises and the participatory prioritisation process. However, a key limitation was the lack of engagement from certain groups. Non-cyclists, potential cyclists, and existing cyclists from other groups (such as recreational cyclists, children who cycle, or food delivery drivers/couriers) were not well recorded through either active or passive engagement exercises in this study. These should be key additions in future research, which should discover how to include and engage those that would not have attended the survey, been a data point in the study, or attended an interview. These above points should be considered by government and researchers as they design and use such tools.

In terms of future work, additional research should consider the growing interest in understanding whether integrating the technique of immersion (e.g., through virtual reality type environments or narrative immersion) is helpful for the successful deployment of cycling DPPs. It could facilitate more insight, higher levels of engagement, and more empathy in the process (Van Leeuwen et al. 2018; Gordon, Schirra, and Hollander 2011; Çöltekin, Lokka, and Zahner 2016). Many studies have investigated the use of bikes in immersive environments (such as head-mounted virtual reality headsets, and immersive cave automatic virtual environments), but these have been limited to collecting biometric information, health information, and understanding navigation techniques and have not been used to inform infrastructure planning (Pedroli et al. 2018; Gaggioli et al. 2017; Chuang et al. 2003; Bialkova, Ettema, and Dijst 2018). As this avenue of exploration was not possible for this study, it could be investigated in further work. 
Future research should also work to better understand socio-technical challenges for local councils, the proposed most likely end users, and others in moving beyond PPGIS approaches into integrating these with similar bicycle PSS approaches to this study. This would investigate the bottlenecks in adoption of using such participatory analytics driven PSS tools.

\section{Conclusion}

As many cities around the world grapple with the challenge of improving active transport infrastructure there is an increasing need for both participatory and evidence-based planning tools which can be used to retrofit our cities with better bicycle infrastructure. In this paper a bicycle infrastructure planning support tool is presented which takes into account both passive and active citizen engagement. The research builds upon the body of work in PPGIS and PSS to develop and evaluate an interactive tool which aims to prioritise future bicycle infrastructure as directly informed by the users of this infrastructure, the local community.

During this research, it is also worth noting and valuable to reflect that there was an exponential increase in the number of publicly available applications using human movement and activity data. This was supercharged by the need for individuals and authorities to understand movement and activity data in the context of the COVID-19 pandemic. Large technology companies are leading the way (for example, Facebook, SafeGraph, Cuebiq, Google, and Mapbox) by sharing passive mobility data to help assist with planning during this crisis. As such, at a time when passive data is being increasingly shared with the public and government and behaviours are being assumed, it could not be more important to emphasise the integration of active participation within this - to create a balanced approach and to match the desires of the participants in this study.

High-quality cycling infrastructure can be a significant investment, and constrained government budgets must balance competing priorities. Thus, investment decisions must be guided by sound analysis and transparent decision support tools. Effective citizen engagement improves the quality of information being developed and ensures that the government can proactively deal with emerging issues. The tool developed in this research enables citizens to identify priorities for themselves and share in decision-making, thereby assuming more ownership of solutions and more responsibility for their implementation. This fosters a sense of mutuality and empowerment, which reduces the risks of implementation and strengthens the resilience of future transport infrastructure.

\section{References}

1. Aldred, Rachel, Bridget Elliott, James Woodcock, and Anna Goodman. 2017. “Cycling Provision Separated from Motor Traffic: A Systematic Review Exploring Whether Stated Preferences Vary by Gender and Age." Transport Reviews 37 (1): $29-55$. https://doi.org/10.1080/01441647.2016.1200156. 
2. Alvarez León, Luis F. 2019. "Eyes on the Road: Surveillance Logics in the Autonomous Vehicle Economy." Surveillance and Society 17 (1-2): 198-204. https://doi.org/10.24908/ss.v17i1/2.12932.

3. Andrejevic, Mark. 2014. “Big Data, Big Questions| the Big Data Divide.” International Journal of Communication 8: 17.

4. Australian Bureau of Statistics. 2016a. “Counting Persons, Place of Usual Residence 2016 Census.” Tablebuilder. 2016.

5. Australian Bureau of Statistics. 2016b. “Mesh Blocks.” 2016. https://www.abs.gov.au/ausstats/abs@.nsf/Lookup/by Subject/1270.0.55.001 July 2016 Main Features Mesh Blocks (MB) 10012.

6. Bialkova, Svetlana, Dick Ettema, and Martin Dijst. 2018. “Urban Future: Unlocking Cycling with VR Applications.” In 2018 IEEE Workshop on Augmented and Virtual Realities for Good, VAR4Good 2018, 1-5. IEEE. https://doi.org/10.1109/VAR4GOOD.2018.8576888.

7. Branion-Calles, Michael, Trisalyn Nelson, and Meghan Winters. 2017. “Comparing Crowdsourced Near-Miss and Collision Cycling Data and Official Bike Safety Reporting." Transportation Research Record: Journal of the Transportation Research Board 2662: 1-11. https://doi.org/10.1113/jphysiol.1993.sp019755.

8. Carver, S., A. Evans, R. Kingston, and I. Turton. 2001. “Public Participation, GIS, and Cyberdemocracy: Evaluating on-Line Spatial Decision Support Systems." Environment and Planning B: Planning and Design 28 (6): 907-21. https://doi.org/10.1068/b2751t.

9. Chuang, Tien Yow, Chih Hung Chen, Hwa Ann Chang, Hui Chen Lee, Cheng Lian Chou, and Ji Liang Doong. 2003. “Virtual Reality Serves as a Support Technology in Cardiopulmonary Exercise Testing." Presence: Teleoperators and Virtual Environments 12 (3): 326-31. https://doi.org/10.1162/105474603765879567.

10. Coghlan, David, and Mary Brydon-Miller. 2014. “Collaborative Data Analysis.” In The SAGE Encyclopedia of Action Research, 12224. https://doi.org/10.4135/9781446294406.n59.

11. Çöltekin, A, I Lokka, and M Zahner. 2016. “On the Usability and Usefulness of 3D (Geo)Visualizations - A Focus on Virtual Reality Envrionments." ISPRS - International Archives of the Photogrammetry, Remote Sensing and Spatial Information Sciences XLI-B2 (June): 387-92. https://doi.org/10.5194/isprs-archives-XLI-B2-387-2016.

12. Falco, Enzo, and Reinout Kleinhans. 2018. “Digital Participatory Platforms for Co-Production in Urban Development: A Systematic Review." International Journal of E-Planning Research 7 (3): 1-27. https://doi.org/10.4018/IJEPR.2018070105.

13. Filonik, Daniel, Markus Rittenbruch, and Marcus Foth. 2014. “Participatory Data Analytics Collaborative Interfaces for Data Composition and Visualisation." VINCI '14 Proceedings of the 7th International Symposium on Visual Information Communication and Interaction Pages 248, 248-49. https://doi.org/10.1145/2636240.2636873.

14. Gaggioli, Andrea, Luca Greci, Sara Arlati, Marco Stramba-Badiale, Elisa Pedroli, Desirée Colombo, Silvia Serino, Pietro Cipresso, and Giuseppe Riva. 2017. "'Positive Bike' - An Immersive Biking Experience for Combined Physical and Cognitive Training of Elderly Patients." Annual Review of CyberTherapy and Telemedicine 15 (December): 196-99.

15. Google. 2018. “GTFS Static Overview I Static Transit । Google Developers.” 2018. https://developers.google.com/transit/gtfs/.

16. Gordon, Eric, Steven Schirra, and Justin Hollander. 2011. “Immersive Planning: A Conceptual Model for Designing Public Participation with New Technologies." Environment and Planning B: Planning and Design 38 (3): 505-19. https://doi.org/10.1068/b37013.

17. Hickman, Robin, and Marco Dean. 2018. "Incomplete Cost-Incomplete Benefit Analysis in Transport Appraisal." Transport Reviews 38 (6): 689-709. https://doi.org/10.1080/01441647.2017.1407377.

18. Kenworthy, Jeffery. 2012. “Don't Shoot Me I'm Only the Transport Planner (Apologies to Sir Elton John).” World Transport Policy and Practice 18 (4): 6-26.

19. Kenworthy, Jeffrey R., and Felix B. Laube. 1999. "Patterns of Automobile Dependence in Cities: An International Overview of Key Physical and Economic Dimensions with Some Implications for Urban Policy." Transportation Research Part A: Policy and Practice 33 (7-8): 691-723. https://doi.org/10.1016/S0965-8564(99)00006-3.

20. Leeuwen, Jos P. Van, Klaske Hermans, Antti Jylhä, Arnold Jan Quanjer, and Hanke Nijman. 2018. “Effectiveness of Virtual Reality in Participatory Urban Planning." ACM International Conference Proceeding Series, 128-36.

https://doi.org/10.1145/3284389.3284491. 
21. Lock, Oliver, and Christopher Pettit. 2020. “Social Media as Passive Geo-Participation in Transportation Planning - How Effective Are Topic Modelling \& Sentiment Analysis in Comparison with Citizen Surveys?" Geo-Spatial Information Science.

22. Lovelace, Robin, Anna Goodman, Rachel Aldred, Nikolai Berkoff, Ali Abbas, and James Woodcock. 2017. “The Propensity to Cycle Tool: An Open Source Online System for Sustainable Transport Planning." Journal of Transport and Land Use 10 (1): 505-28. https://doi.org/10.5198/jtlu.2016.862.

23. Milakis, Dimitris, and Konstantinos Athanasopoulos. 2014. “What about People in Cycle Network Planning? Applying Participative Multicriteria GIS Analysis in the Case of the Athens Metropolitan Cycle Network." Journal of Transport Geography 35: 120-29. https://doi.org/10.1016/j.jtrangeo.2014.01.009.

24. Nelson, Trisalyn A., Taylor Denouden, Benjamin Jestico, Karen Laberee, and Meghan Winters. 2015. “BikeMaps.Org: A Global Tool for Collision and Near Miss Mapping." Frontiers in Public Health 3 (March): 1-8. https://doi.org/10.3389/fpubh.2015.00053.

25. NSW Government. 2019. “ELVIS - Elevation and Depth - Foundation Spatial Data.” NSW Spatial Services Portal. 2019. https://elevation.fsdf.org.au/.

26. Oja, P., S. Titze, A. Bauman, B. de Geus, P. Krenn, B. Reger-Nash, and T. Kohlberger. 2011. “Health Benefits of Cycling: A Systematic Review." Scandinavian Journal of Medicine and Science in Sports 21 (4): 496-509. https://doi.org/10.1111/j.16000838.2011.01299.x.

27. OpenTripPlanner. 2018. “OpenTripPlanner.” 2018. http://www.opentripplanner.org/.

28. Pedroli, Elisa, Luca Greci, Desirèe Colombo, Silvia Serino, Pietro Cipresso, Sara Arlati, Marta Mondellini, et al. 2018. “Characteristics, Usability, and Users Experience of a System Combining Cognitive and Physical Therapy in a Virtual Environment: Positive Bike." Sensors (Switzerland) 18 (7). https://doi.org/10.3390/s18072343.

29. Petersen, Andrew Boyles. 2019. “Scoot over Smart Devices: The Invisible Costs of Rental Scooters." Surveillance and Society 17 (12): 191-97. https://doi.org/10.24908/ss.v17i1/2.13112.

30. Pettit, C. J., S. N. Lieske, and S. Z. Leao. 2016. “Big Bicycle Data Processing: From Personal Data to Urban Applications.” ISPRS Annals of the Photogrammetry, Remote Sensing and Spatial Information Sciences 3 (July): 173-79. https://doi.org/10.5194/isprs-annalsIII-2-173-2016.

31. Searle, Glen, and Crystal Legacy. 2019. "Australian Mega Transport Business Cases: Missing Costs and Benefits." Urban Policy and Research 37 (4): 458-73. https://doi.org/10.1080/08111146.2019.1663727.

32. Shareabouts. 2012. "Github - Shareabouts." 2012. https://github.com/openplans/shareabouts\%0A.

33. Sieber, Renee. 2006. "Public Participation Geographic Information Systems: A Literature Review and Framework." Annals of the Association of American Geographers 96 (3): 491-507.

34. Thomas, James J., and Kristin a. Cook. 2006. "Visualization Viewpoints: A Visual Analytics Agenda." IEEE Computer Graphics and Applications 26 (February): 10-13. https://doi.org/10.1109/MCG.2006.5.

35. Transport for NSW. 2019a. “Centre for Road Safety I Interactive Crash Statistics.” TfNSW Centre for Road Safety. 2019. https://roadsafety.transport.nsw.gov.au/statistics/interactivecrashstats/index.html.

36. Transport for NSW, 2019b. “City of Sydney - Cycleway Data.” Open Data I Transport for NSW. 2019. https://opendata.transport.nsw.gov.au/dataset/cycle-network-city-sydney.

37. Transport for NSW. 2019c. “Cycleway Data.” Open Data I Transport for NSW. 2019. https://opendata.transport.nsw.gov.au/dataset/cycleway-data.

38. Uber. 2020. “Uber Newsroom I Uber Announces New Mobility Infrastructure Initiative for Safe Streets.” 2020. https://www.uber.com/newsroom/city-mobility-campaign/.

39. Woodcock, James, Ali Abbas, Alvaro Ullrich, Marko Tainio, Robin Lovelace, Thiago H. Sá, Kate Westgate, and Anna Goodman. 2018. “Development of the Impacts of Cycling Tool (ICT): A Modelling Study and Web Tool for Evaluating Health and Environmental Impacts of Cycling Uptake." PLoS Medicine 15 (7): 1-22. https://doi.org/10.1371/journal.pmed.1002622.

40. Zuboff, Shoshana. 2019. The Age of Surveillance Capitalism: The Fight for a Human Future at the New Frontier of Power. Profile Books. 


\section{Appendix 1}

\section{Survey design}
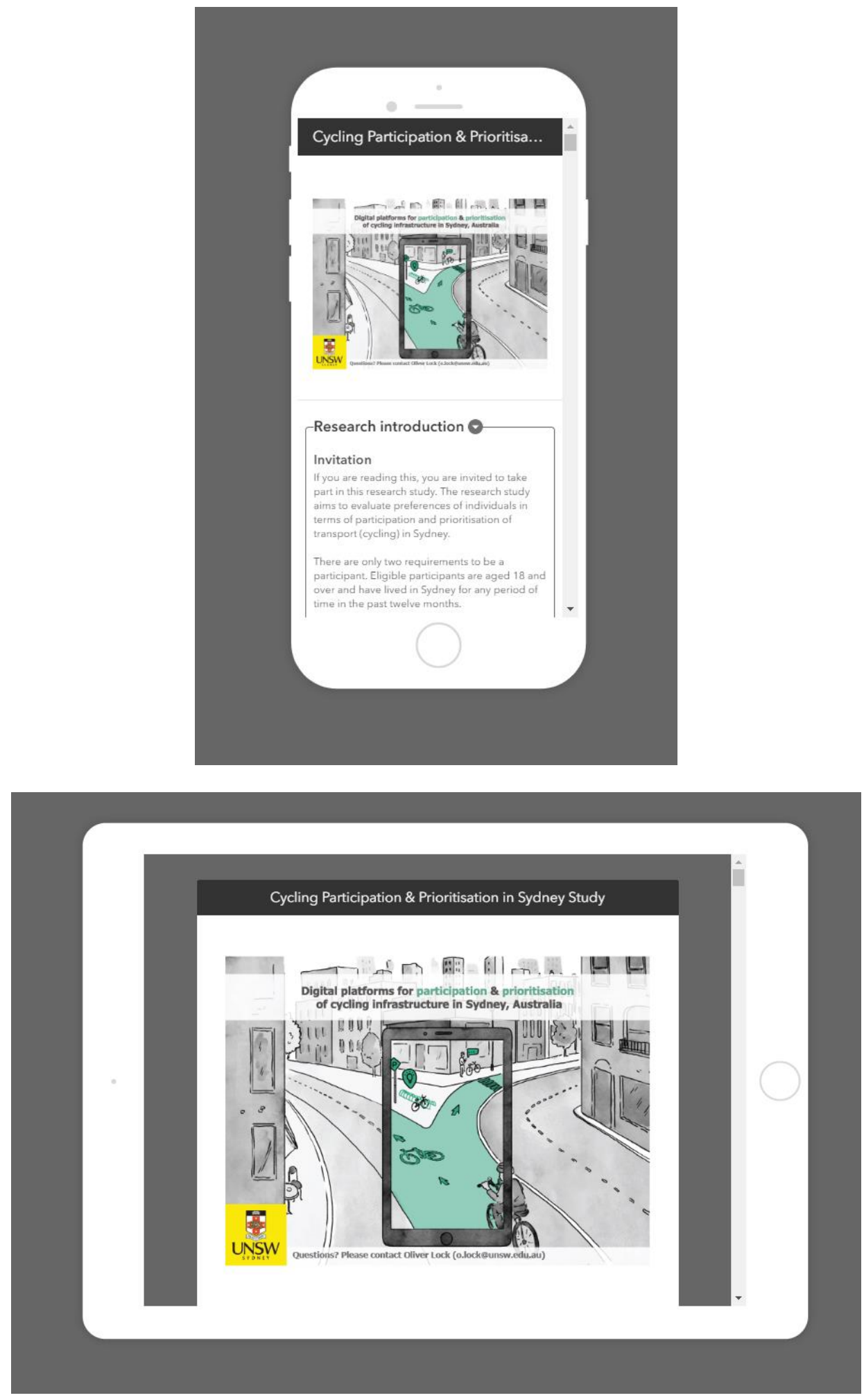

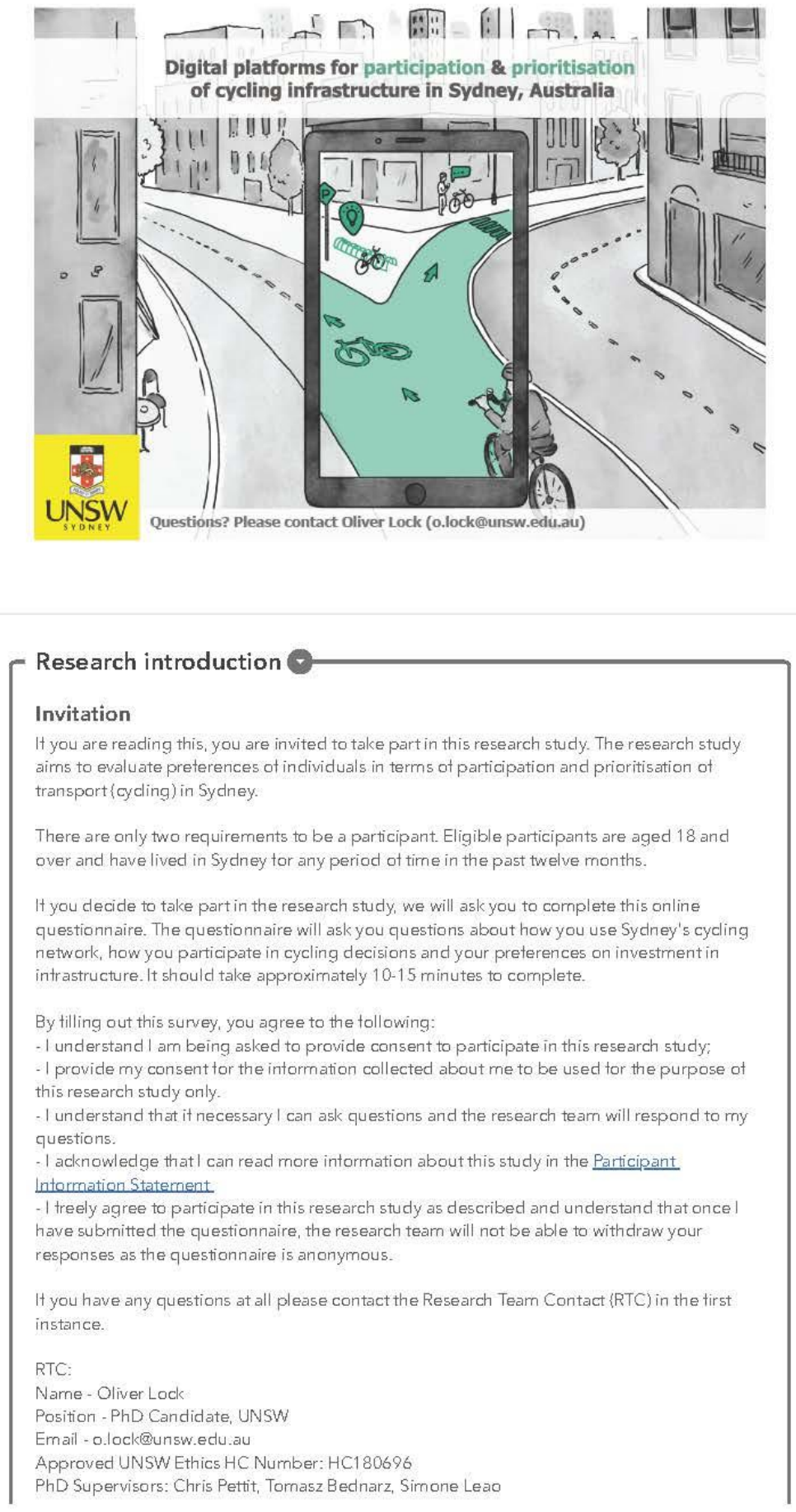


\section{Why are we doing this research?}

We want to understand individual's preferences in participation mechanisms and investment

in cycling infrastructure in Sydney, Australia.

By filling out this survey, you will help us understand how to best use new data and tools in a positive way to influence and prioritise transport decisions.

\section{Will I be compensated?}

As this is personal $\mathrm{PhD}$ research there is no funding attached to this project.

However, to make things interesting and encourage participation, there is a raffle with two prizes. One of the first 25 participants will receive an UberEats voucher valued at \$25 USD $(\sim 40$ AUD). One of the second 25 participants will receive the same.

Should the winners not want these vouchers, they will be donated to World Bicycle Relief (https:/1giveau.worldbicyclerelieforg). This not-for-profit organisation are currently distributing bicycles to front-line health workers in areas around the world that currently need them.

\section{The Basics}

1) Which age bracket do you fall into?*

You must be 18 years old, or older, to participate in this study.

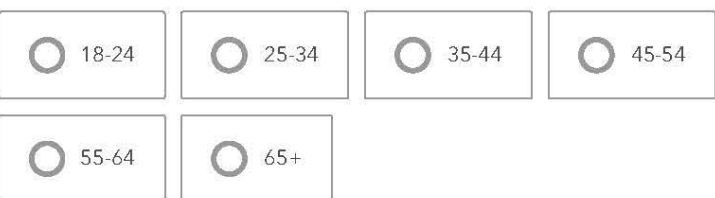

\section{2) Gender*}

This is to ensure the survey has reached a sound diversity of participants.

3) Please specify the postcode in which you usually reside*

This is to ensure that a diversity of home locations are considered in the survey. If you have recently moved States, please use your previous Sydney postcode.

4) Do you currently live, or have you lived, in Sydney or with in $200 \mathrm{~km}$ of Sydney in the past twelve months?*

If your answer to this question is 'No' your answers are not eligible for this study.

$$
\text { Yes }
$$

No 


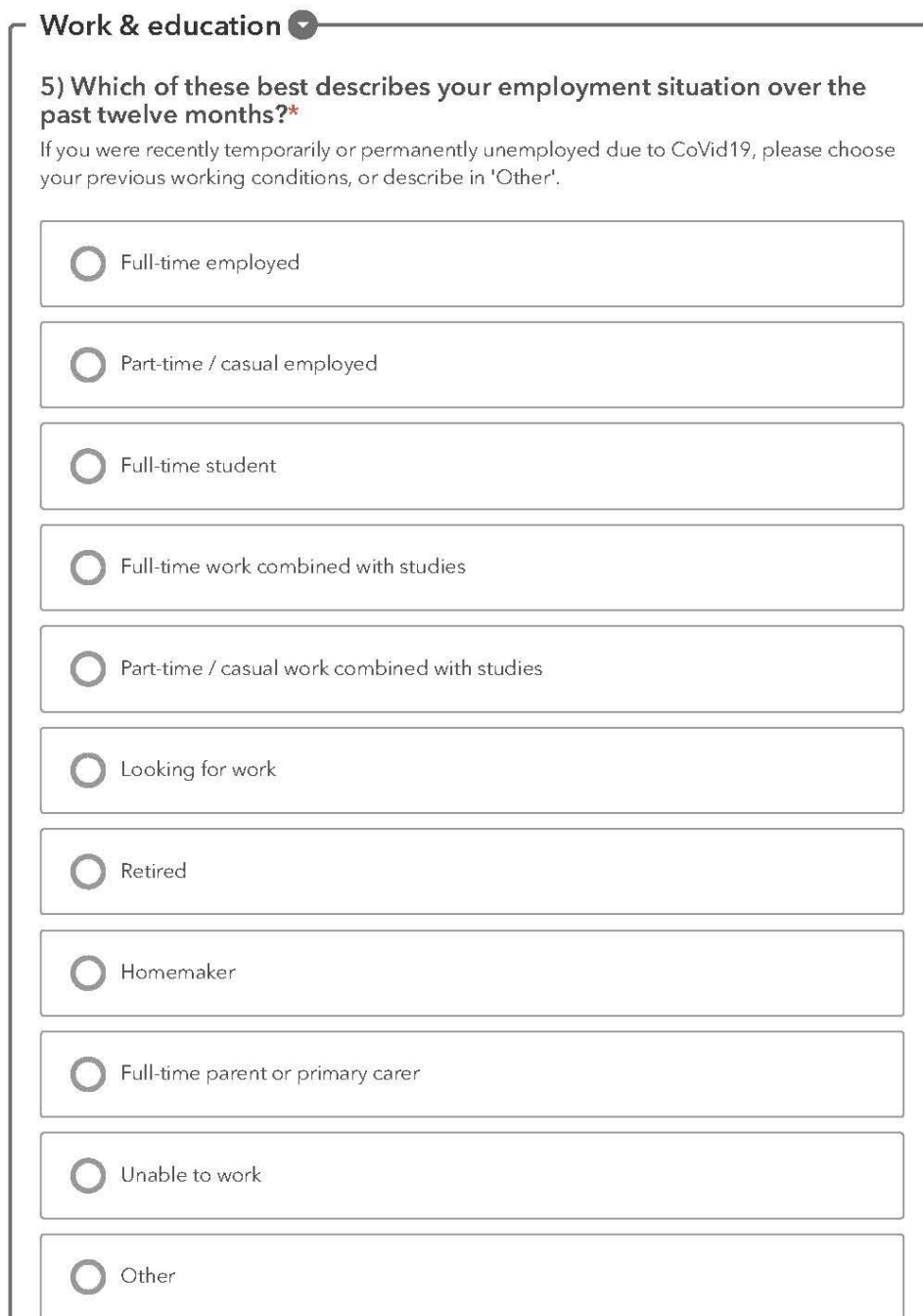

6) What is the highest level of education you have completed?*

Up to High School Certificate

High School Certificate

Trade/technical/vocational training

TAFE Certificate I-IV / Diploma.

Advanced Diploma / Associate Degree 
Undergraduate degree (Bachelor)

Graduate Certificate, Diploma, \& Bachelor Honours

Masters Degree

Doctoral Degree

Other

Cycling activities and preferences

7) Have you ridden a bicycle to get around in Sydney in the past twelve months?*

Yes

No

Other

8) In the past year, tick any of the following travel purposes you have used your bike for in Sydney:*

Commuting to and from a workplace

Travelling to and from education

Cycling for fun and enjoyment

Cycling to visit family and friends

Cycling for shopping trips

Cycling for exercise

Cycling as a group social activity

Cycling to fulfil your employment needs directly (e.g. as a Deliveroo / UberEats / Menulog or other Courier) 
Other

9) Which best describes the frequency you cycle?*

Every day, or close to every day

At least a few times a week

At least a few times a fortnight

At least a few times a month

Less than once a month

I haven't ridden this year

I have never ridden a bike

Other

10a) Physical confidence - how confident are you cycling in general?*

Very confident - I am comfortable riding in almost any environment.

Confident - I am comfortable riding in many environments, but still cautious in some.

Moderately confident - I am comfortable riding in some environments, and cautious in others.

Cautious - I feel cautious riding in many environments, but confident in some.

Very cautious - I feel the need to be cautious in almost any environment.

Other

10b) Navigational confidence / network legibility - how confident are you navigating the cycle network?* 
Confident - I sometimes need to use a map, app or service to get around.

Moderately confident - Around half of my trips I need to check a map, app or service to get around

Not confident - Most of my trips I need more information in order to get around

Very little to no confidence - I am almost never able to navigate without needing to use a map, app or service to get around.

Other

Participation \& engagement in cycling -

11) Which of the following activities related to engaging in cycle planning have you personally been involved in, specifically in Sydney (not including this survey)?*

I was a participant in the 2016 Australian Census

I was a participant in the TfNSW Household Travel Survey (HTS)

I was a participant in a National Cycling Participant Survey (NCPS)

I have attended advocacy group meetings and events

I have posted to my social media profiles about cycling

I have attended physical meetings as a community member concerned about cycling

I have given feedback to a bike plan/proposal/strategy to a local council

I have given feedback to a bike plan / proposal/strategy to a state body

I have used a government, industry or research-led digital participatory pinboarding tool which asked me about cycling

$\square$ My employment has involved providing expertise related to cycling 
I don't think I have ever particioated in activities that could influence cycle planning

Other

12) How satisfied are you with current mechanisms for you to comment ('have your say') on your experiences and preferences for cycling investment in Sydney?*

O

Very unsatisfied Notsatisfied Neutral Satisfied Very satisfied

13) What proportion of your rides have you purposefully logged using apps such as MapMyRide, Riderlog or Strava?*

Almost every ride to all rides $(76 \%-100 \%)$

Most of my rides ( $51.75 \%)$

Less than half of my rides $(26 \%-50 \%)$

Some of my rides $(0-25 \%)$

None of my rides

14) Do you log mostly recreational rides or commuting (to/from work) rides?*

I mostly log recreational rides

I mostly log commuting rides

I log a mixture of these

I don't log my rides

Other

15) Which type of participation would you personally prefer to help improve the cycling network?* 
Passively - I want data about me (e.g. strava, census) to be used to improve the network with minimal effort from my end.

Actively, but with no time - I want very quick ways to be able to individually contribute to improvements to the network.

Actively, with time - I want to be involved and I am willing to give up my own time to contribute to improvements to the network.

16) Do you feel that the CoVID-19 situation has changed your views or behaviours around cycling in any way? What about those around you? How?*

What should we prioritise in Sydney's cycling network? 17) What would you rate Sydney's cycling network out of 10 ?*

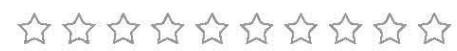

18) Do you have any reasons that come to mind that informed that rating?*

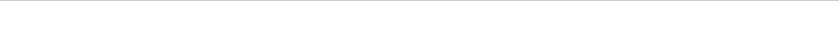

19A) How important are the following factors, to you personally, in improving the cycle network in Sydney?

\begin{tabular}{|c|c|c|c|c|c|}
\hline & $\begin{array}{c}\text { Very } \\
\text { unimportant }\end{array}$ & Unimportant & Neither, nor & Important & $\begin{array}{c}\text { Very } \\
\text { importan }\end{array}$ \\
\hline $\begin{array}{l}\text { A) Building more } \\
\text { separated cycleways } \\
\text { (off-road and away } \\
\text { from traffic)* }\end{array}$ & & & 0 & & \\
\hline $\begin{array}{l}\text { B) Creating a } \\
\text { continuous network } \\
\text { that doesn't stop and } \\
\text { start* }\end{array}$ & & & $\Omega$ & & \\
\hline $\begin{array}{l}\text { C) Designing safer } \\
\text { environments in }\end{array}$ & $n$ & $n$ & ค & $n$ & n \\
\hline
\end{tabular}




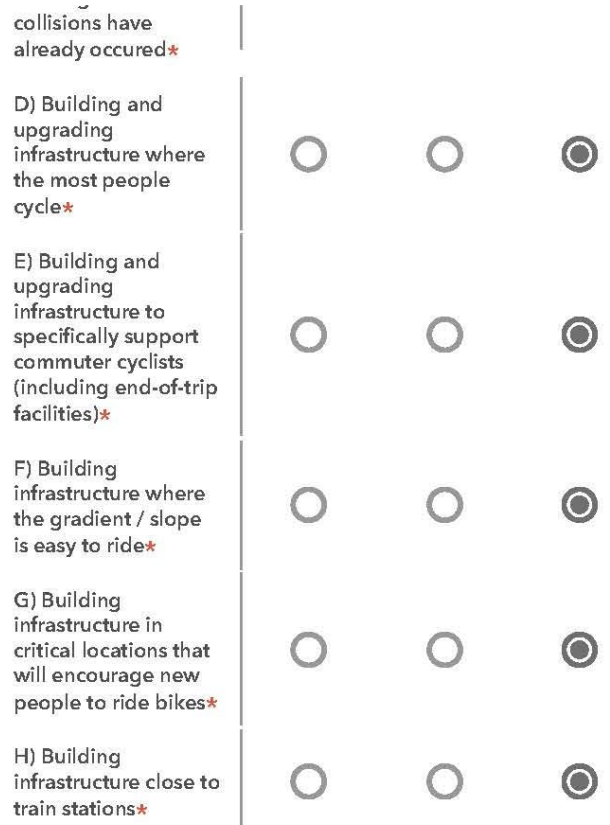

000

000

000

000 O 00<smiles>[O]</smiles><smiles>O</smiles><smiles>O=CO</smiles><smiles>O</smiles>

19B) If you can only choose one as the most important, which would you choose?

-Please Select-

20) What are some important factors to you that might be missing from above?*

Where should we spend more money on cycling?

21A) What and where would be your top cycling improvement to Sydney be? Draw it on this map.

To draw a shape click on one of the icons in the top right. The star-shaped icon lets you draw a complex shape, while the other expects a square, triangle or circle shape. Hold your mouse button and draw a shape around an area making sure to fully enclose it. You can only draw one shape!

\begin{tabular}{|c|c|c|}
\hline+ & a & 8 \\
\hline- & & $\infty$ \\
\hline & & \\
\hline$\epsilon$ & & \\
\hline
\end{tabular}




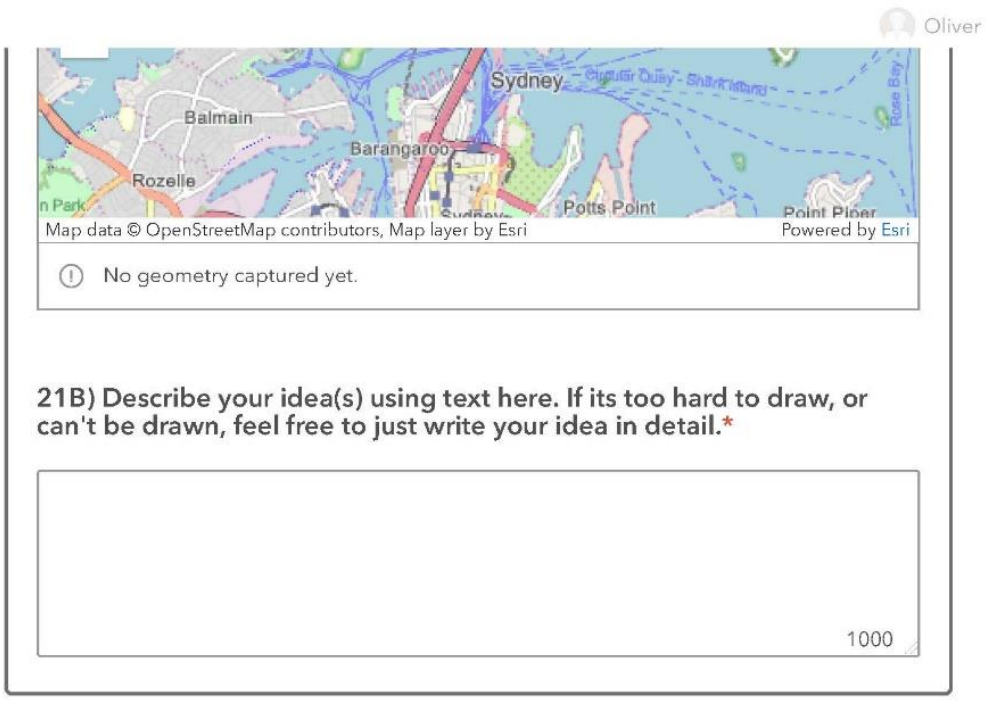

22) Final question - Please add any more information you would like to supply to this research here - anecdotes, ideas, barriers you have faced. 


\section{Appendix 2}

Table 1 Description of elements within participatory prioritisation index

\begin{tabular}{|c|c|c|c|c|c|}
\hline ID & $\begin{array}{l}\text { Priority } \\
\text { Description }\end{array}$ & $\underline{\text { Metric }}$ & $\underline{\text { Prioritise }}$ & Method & Data Source \\
\hline A & $\begin{array}{l}\text { Priority should be given } \\
\text { to areas with limited off- } \\
\text { street cycleways. }\end{array}$ & $\begin{array}{l}\text { KM of separated } \\
\text { or off-street } \\
\text { cycleway (shared } \\
\text { or designated } \\
\text { pedestrian- } \\
\text { shared) }\end{array}$ & $\begin{array}{l}\text { Areas with low KMs } \\
\text { of separated or off- } \\
\text { street cycleways } \\
\text { (shared or designated } \\
\text { pedestrian shared) }\end{array}$ & $\begin{array}{l}\text { Calculated KM of } \\
\text { infrastructure within } \\
\text { a hexagonal unit. }\end{array}$ & $\begin{array}{l}\text { Cycleway data from NSW } \\
\text { government (Transport for NSW } \\
\text { 2019c) combined with cycleway } \\
\text { data from City of Sydney } \\
\text { (Transport for NSW 2019b). }\end{array}$ \\
\hline B & $\begin{array}{l}\text { Priority should be given } \\
\text { to areas which connecting } \\
\text { existing network of off- } \\
\text { street cycleways. }\end{array}$ & $\begin{array}{l}\text { KM of dangling } \\
\text { nodes }\end{array}$ & $\begin{array}{l}\text { Areas where a } \\
\text { separated or off-street } \\
\text { cycleway end, and } \\
\text { there is no connection } \\
\text { within } 100 \text { metres of } \\
\text { that end point }\end{array}$ & $\begin{array}{l}\text { Total number of } \\
\text { 'dangling nodes' } \\
\text { within hexagonal } \\
\text { unit. }\end{array}$ & $\begin{array}{l}\text { Cycleway data from NSW } \\
\text { government (Transport for NSW } \\
\text { 2019c) combined with cycleway } \\
\text { data from City of Sydney } \\
\text { (Transport for NSW 2019b). }\end{array}$ \\
\hline $\mathrm{C}$ & $\begin{array}{l}\text { Priority should be given } \\
\text { to improving the safety of } \\
\text { areas where cyclists have } \\
\text { crashed. }\end{array}$ & $\begin{array}{l}\text { Number of } \\
\text { cycling incidents }\end{array}$ & $\begin{array}{l}\text { Areas which } \\
\text { experience a high } \\
\text { volume of cycling } \\
\text { incidents (crashes) }\end{array}$ & $\begin{array}{l}\text { Raw number of } \\
\text { cycling-related } \\
\text { incidents within } \\
\text { hexagonal unit }\end{array}$ & $\begin{array}{l}\text { Geolocation of cycling accidents } \\
\text { from TfNSW Centre for Road } \\
\text { Safety. (Transport for NSW 2019a). } \\
\text { Years available: 2014-2018. Type of } \\
\text { crash (Pedal Cycle). }\end{array}$ \\
\hline $\mathrm{D}$ & $\begin{array}{l}\text { Priority should be given } \\
\text { to where estimated } \\
\text { volumes of all cyclists use } \\
\text { the network }\end{array}$ & $\begin{array}{l}\text { Number of Strava } \\
\text { cyclists (weighted } \\
\text { to official } \\
\text { cycleway } \\
\text { statistics) }\end{array}$ & $\begin{array}{l}\text { Areas used by many } \\
\text { Strava cyclists } \\
\text { (weighted to official } \\
\text { counters) }\end{array}$ & $\begin{array}{lr}\text { Total volume of } \\
\text { cyclists } & \text { passing } \\
\text { through } & \text { hexagonal } \\
\text { unit } & \end{array}$ & $\begin{array}{l}\text { Strava trip data weighted to } \\
\text { official Roads and Maritime } \\
\text { Services (RMS), now TfNSW } \\
\text { cycleway counters. }\end{array}$ \\
\hline $\mathrm{F}$ & $\begin{array}{l}\text { Priority should be given } \\
\text { to corridors that are } \\
\text { currently used for } \\
\text { commuting purposes } \\
\text { (current Census } \\
\text { commuters) }\end{array}$ & $\begin{array}{l}\text { Existing } \\
\text { demand }\end{array}$ & $\begin{array}{l}\text { Areas along 'desire } \\
\text { line' of current }^{\prime} \\
\text { cycling commuters }\end{array}$ & $\begin{array}{l}\text { SA2 to SA2 matrix } \\
\text { with desire lines } \\
\text { calculated between } \\
\text { them for existing } \\
\text { cyclist commuters } \\
\text { using a Triangular } \\
\text { Irregular Network } \\
\text { (TIN) }\end{array}$ & $\begin{array}{l}2016 \text { Census Method of Travel to } \\
\text { Work (Australian Bureau of } \\
\text { Statistics 2016a) }\end{array}$ \\
\hline
\end{tabular}




\begin{tabular}{|c|c|c|c|c|c|}
\hline$G$ & $\begin{array}{l}\text { Priority should be given } \\
\text { to areas within a 10- } \\
\text { minute cycle to a train } \\
\text { station }\end{array}$ & $\begin{array}{l}\text { Cycle accessibility } \\
\text { model }\end{array}$ & $\begin{array}{l}\text { Number of train / } \\
\text { metro stations }\end{array}$ & $\begin{array}{l}\text { Meshblock based } \\
\text { accessibility to train } \\
\text { stations }\end{array}$ & $\begin{array}{l}\text { Meshblocks (Australian Bureau of } \\
\text { Statistics 2016b), GTFS (Google } \\
\text { 2018) and OpenTripPlanner } \\
\text { (OpenTripPlanner 2018). }\end{array}$ \\
\hline $\mathrm{H}$ & $\begin{array}{l}\text { Priority should be given } \\
\text { to areas with a cyclable } \\
\text { gradient }\end{array}$ & Slope & Low Slope (\%) & $\begin{array}{l}\text { Digital Elevation } \\
\text { Model / Slope } \\
\text { Calculations from } 1 \mathrm{M} \\
\text { LIDAR. }\end{array}$ & $\begin{array}{l}\text { ELVIS, NSW Spatial (NSW } \\
\text { Government 2019) }\end{array}$ \\
\hline I & Converted short car trips & $\begin{array}{l}\text { Potential short car } \\
\text { trips }\end{array}$ & $\begin{array}{l}\text { High volume of } \\
\text { potential conversions }\end{array}$ & $\begin{array}{l}\text { Estimation of volume } \\
\text { of potential trips } \\
\text { generated at origins } \\
\text { and generations if } \\
\text { cycle improvements } \\
\text { were made. The } \\
\text { distribution of this is } \\
\text { based on the age and } \\
\text { distance profile of } \\
\text { existing cycle } \\
\text { commuters and the } \\
\text { number of short car } \\
\text { trips currently fitting } \\
\text { the same profile in } \\
\text { each statistical area. }\end{array}$ & $\begin{array}{l}\text { ABS Census Method of Travel to } \\
\text { Work (Age, Mode, Trip Distance). } \\
\text { (Australian Bureau of Statistics } \\
\text { 2016a) }\end{array}$ \\
\hline $\mathrm{J}$ & $\begin{array}{l}\text { Citizen } \\
\text { locations for }\end{array}$ & $\begin{array}{l}\text { Citizen voted } \\
\text { locations }\end{array}$ & $\begin{array}{l}\text { High volume of } \\
\text { citizen voted } \\
\text { locations }\end{array}$ & $\begin{array}{l}\text { Survey sent where } \\
\text { citizens draw explicit } \\
\text { spatial shapes. Count } \\
\text { the number of these } \\
\text { shapes which fall } \\
\text { within each hexagon. }\end{array}$ & $\begin{array}{l}\text { ArcGIS Online Spatial Survey } \\
\text { (Survey123) as explained in the } \\
\text { method section of this document. }\end{array}$ \\
\hline
\end{tabular}

\section{Appendix 3}

Table 2 Survey results summary

Age

18-24

25-34

35-44
Count $(\mathrm{n}=280)$

14

66

84
Percentage

$5 \%$

$23.57 \%$

$30 \%$ 
45-54

55-64

$65+$
71

36

9
$25.36 \%$

$12.86 \%$

$3.21 \%$

\section{Gender}

$\begin{array}{lll}\text { Male } & 181 & 64.6 \% \\ \text { Female } & 96 & 34.3 \% \\ \text { Non-binary } & 2 & 0.7 \% \\ \text { Did not specify } & 1 & 0.4 \%\end{array}$

\section{Employment status}

Full-time employed 208 $74.29 \%$

Part-time / casual employed 26

$9.29 \%$

Full-time student 11

$3.93 \%$

Full-time work combined with studies

2

$0.71 \%$

Part-time / casual work combined with studies

Looking for work

Retired

Full-time parent or primary carer 3

$1.07 \%$

Other

\section{Education}

Up to High School Certificate

$0.71 \%$

High School Certificate

Trade/technical/vocational training

TAFE Certificate I-IV / Diploma.

0

Advanced Diploma / Associate Degree

20

$2.86 \%$

Undergraduate degree (Bachelor)

8

$0 \%$

Graduate Certificate, Diploma \& Honours

Master's Degree

53

$2.86 \%$

Doctoral Degree

89

$24.29 \%$

Other

30

$18.93 \%$

$31.79 \%$

2

$10.71 \%$

$0.71 \%$

\section{Bicycle travel purposes}

$\begin{array}{llc}\text { Commuting to and from a workplace } & 213 & 76.07 \% \\ \text { Travelling to and from education } & 34 & 12.14 \% \\ \text { Cycling for fun and enjoyment } & 247 & 88.21 \% \\ \text { Cycling to visit family and friends } & 162 & 57.86 \%\end{array}$




$\begin{array}{lll}\text { Cycling for shopping trips } & 176 & 62.86 \% \\ \text { Cycling for exercise } & 226 & 80.71 \% \\ \text { Cycling as a group social activity } & 134 & 47.86 \% \\ \text { Cycling to fulfil your employment needs directly (e.g., as a Deliveroo } & 4 & 1.43 \% \\ \text { / UberEATS / Menulog or other Courier) } & & \\ \text { Other } & 25 & 8.93 \%\end{array}$

\section{Cycling frequency}

Every day, or close to every day 101

$36.07 \%$

At least a few times a week

100

$35.71 \%$

At least a few times a fortnight

32

$11.43 \%$

At least a few times a month

23

$8.21 \%$

Less than once a month

14

$5 \%$

I haven't ridden this year

10

$3.57 \%$

\section{Cycling confidence}

Very confident - I am comfortable riding in almost any environment. 103 $36.79 \%$

Confident - I am comfortable riding in many environments, but still 116

cautious in some.

Moderately confident - I am comfortable riding in some 44

environments, and cautious in others.

Cautious - I feel cautious riding in many environments, but confident 14

in some.

Very cautious - I feel the need to be cautious in almost any 3

environment.

\section{Navigational confidence}

Very confident - I almost never need to use a map, app or service to 37

get around.

Confident - I sometimes need to use a map, app or service to get 131 around.

Moderately confident - Around half of my trips I need to check a map, 71

app or service to get around.

Not confident - Most of my trips I need more information in order to 24

get around.

Very little to no confidence - I am almost never able to navigate 8

without needing to use a map, app or service to get around.

Other 


\section{Engagement in cycle planning}

I was a participant in the 2016 Australian Census

I was a participant in the TfNSW Household Travel Survey (HTS) 13

$63.93 \%$

I was a participant in a National Cycling Participant Survey (NCPS) 14

I have attended advocacy group meetings and events 57

$4.64 \%$

I have posted to my social media profiles about cycling

154

$5 \%$

I have attended physical meetings as a community member 54

$20.36 \%$

concerned about cycling

I have given feedback to a bike plan / proposal / strategy to a local 156

$55.71 \%$

council

I have given feedback to a bike plan / proposal / strategy to a state 88

body

I have used a government, industry or research-led digital 42

$15 \%$

participatory pin-boarding tool which asked me about cycling

My employment has involved providing expertise related to cycling 51

$18.21 \%$

I don't think I have ever participated in activities that could influence 40

cycle planning

Other

\section{Satisfaction with participation mechanisms}

Very unsatisfied

$11.79 \%$

Not satisfied

$42.5 \%$

Neutral

Satisfied

$8.93 \%$

Very satisfied

3

$1.07 \%$

\section{Recorded rides}

Almost every ride to all rides (76\% - 100\%)

$30.36 \%$

Most of my rides (51-75\%)

Less than half of my rides $(26 \%-50 \%)$

Some of my rides (0-25\%)

48

$17.14 \%$

None of my rides

\section{Type of logging}

I mostly log recreational rides

I mostly log commuting rides 


\begin{tabular}{lll}
\hline I don't log my rides & 102 & $36.43 \%$ \\
\hline Other & 7 & $2.50 \%$
\end{tabular}

\section{Preferred engagement format}

Passively - I don't want anything that I do to influence the network. $2 \quad 0.71 \%$

$\begin{array}{ll}\text { Passively - I want data about me (e.g., strava, census) to be used to } 37 & 13.21 \%\end{array}$

improve the network with minimal effort from my end.

Actively, but with no time - I want very quick ways to be able to $154 \quad 55 \%$

individually contribute to improvements to the network.

$\begin{array}{ll}\text { Actively, with time - I want to be involved and I am willing to give up } \quad 87 & 31.07 \%\end{array}$

my own time to contribute to improvements to the network.

\section{What would you rate Sydney's network out of 10?}

$\begin{array}{lll}\text { Average } & 3.8 / 10 & 6.07 \% \\ \mathbf{1} & 17 & 16.07 \% \\ \mathbf{3} & 45 & 24.29 \% \\ \mathbf{4} & 68 & 21.43 \% \\ \mathbf{5} & 15.71 \% & 10 \% \\ \mathbf{6} & 60 & 4.29 \% \\ \mathbf{8} & 44 & 1.43 \% \\ \mathbf{9} & 28 & 0 \%\end{array}$




\section{Appendix 4}

Table 3 Number one priority, if can only pick one

Topic

Number $(\mathbf{n}=\mathbf{2 7 5})$

Percent
A) Building more separated cycleways (off-road 111
$39.64 \%$
and away from traffic)
B) Creating a continuous network that doesn't 116
$41.43 \%$
stop and start
C) Designing safer environments in areas where 19
$6.79 \%$

crashes, doorings and collisions have already

occurred

D) Building and upgrading infrastructure 3

$1.07 \%$

where the most people cycle

E) Building and upgrading infrastructure to 7

specifically support commuter cyclists

(including end-of-trip facilities)

F) Building infrastructure where the gradient / 4 slope is easy to ride

G) Building infrastructure in critical locations 13

$4.64 \%$

that will encourage new people to ride bikes

$\mathrm{H})$ Building infrastructure close to train stations

$0.71 \%$

Table 4 Thematic summary of survey participants additional factors to prioritise. 7,024 total words. Avg of 25 words per response.

\begin{tabular}{|c|c|c|}
\hline Theme & $\begin{array}{l}\text { Example key words / } \\
\text { codes }\end{array}$ & Key quotes \\
\hline $\begin{array}{l}\text { More education, training and } \\
\text { marketing programs across all } \\
\text { modes (vehicles, bicycles, } \\
\text { pedestrians) to create positive } \\
\text { behaviours, increase safety and } \\
\text { reduce aggression on roads and } \\
\text { cycleways }\end{array}$ & $\begin{array}{l}\text { Education (29), Educate } \\
\text { (2)/Training (4), Attitude } \\
\text { (18), Behaviour (4) }\end{array}$ & $\begin{array}{l}\text { 'More efforts to shift driver } \\
\text { behaviour/attitudes (e.g., evidence of how } \\
\text { building off-road cycling infrastructure } \\
\text { benefits drivers as well as cyclists; } \\
\text { enforcement of } 1.5 \mathrm{~m} \text { passing rules etc)'. } \\
\text { 'Soft measures such as campaigning, } \\
\text { encouraging and educating a wide audience } \\
\text { on benefits of cycling, safe routes to use, body } \\
\text { language and confidence on a bike, bike } \\
\text { training courses etc. There needs to be a } \\
\text { culture shift here in Sydney which I think is } \\
\text { just starting to happen due to COVID'. }\end{array}$ \\
\hline
\end{tabular}




\begin{tabular}{|c|c|c|}
\hline & & $\begin{array}{l}\text { 'Infrastructure alone isn't enough. Most } \\
\text { people feel unsafe riding and behaviour } \\
\text { change programs are necessary to help } \\
\text { facilitate change'. } \\
\text { 'Motor vehicle driver education - we need to } \\
\text { change the culture to remove the aggression } \\
\text { and negative attitude towards cyclists'. }\end{array}$ \\
\hline $\begin{array}{l}\text { Lessening severity of helmet laws } \\
\text { to encourage more cycling trips / } \\
\text { participation }\end{array}$ & Helmet (12) & $\begin{array}{l}\text { 'Repeal Mandatory Helmet Laws, allow } \\
\text { cycling on footpath, allow cyclist crossing on } \\
\text { pedestrian crossing without dismounting, } \\
\text { remove beg buttons'. } \\
\text { 'Prioritise lights for bikes not cars, reduce fines } \\
\text { to more sensible amounts, repeal mandatory } \\
\text { helmet and bicycle bell laws'. } \\
\text { 'Relaxation of compulsory helmet laws. } \\
\text { Small gains in road safety cost the community } \\
\text { massively in lower participation rates and } \\
\text { adverse outcomes for community health } \\
\text { through inactivity related lifestyle diseases. } \\
\text { Helmets should be optional on off-road } \\
\text { cycling environments (not including } \\
\text { mountain bike trails)'. }\end{array}$ \\
\hline $\begin{array}{l}\text { Increased legal enforcement of } \\
\text { rules which endanger cyclists }\end{array}$ & $\begin{array}{l}\text { Law (9), Enforcement (3), } \\
\text { Legal (5) }\end{array}$ & $\begin{array}{l}\text { 'Removing Mandatory Helmet Laws as the } \\
\text { discourage cycling and create the impression } \\
\text { that cycling is inherently dangerous!' } \\
\text { 'Enforce the minimum passing distance'. } \\
\text { 'Regulate the bike being used especially by } \\
\text { delivery riders that bypass laws'. }\end{array}$ \\
\hline $\begin{array}{l}\text { Additional infrastructure that } \\
\text { allows children to ride to school }\end{array}$ & School (8), kid (6), child (9) & $\begin{array}{l}\text { 'Building infrastructure that enables children } \\
\text { to ride to school'. }\end{array}$ \\
\hline
\end{tabular}




\begin{tabular}{|c|c|c|}
\hline & & $\begin{array}{l}\text { 'We know the morning and afternoon school } \\
\text { run put massive loads on the road network } \\
\text { and unfortunately it is often very short trips } \\
\text { that are easily manageable, and more } \\
\text { enjoyable, by bike'. }\end{array}$ \\
\hline $\begin{array}{l}\text { Reducing the speed of vehicles in } \\
\text { areas with pedestrians and } \\
\text { cyclists }\end{array}$ & Speed (15) & $\begin{array}{l}\text { 'Low speed local roads to create safer } \\
\text { environments for peds and cyclists'. } \\
\text { 'Traffic calming; cars drive too fast and too } \\
\text { dangerously and there is almost no reason not } \\
\text { to drive that way' }\end{array}$ \\
\hline $\begin{array}{l}\text { Increasing width available for } \\
\text { cyclists on roads, shared footpaths } \\
\text { and shared cycleways }\end{array}$ & Wide (8) & $\begin{array}{l}\text { 'For shared paths increasing their widths to } \\
\text { better cater for harmony between pedestrians } \\
\text { and cyclists'. } \\
\text { 'More than anything I just want a nice wide } \\
\text { shoulder. That is what would make the } \\
\text { biggest difference to safety. I prefer to ride on } \\
\text { the road as it flows better than bike paths. } \\
\text { There is less debris and hazards and I don't get } \\
\text { stick behind slow commuters'. } \\
\text { 'So often the infrastructure is only half baked, } \\
\text { like shared paths that are no wider than a } \\
\text { standard footpath'. }\end{array}$ \\
\hline $\begin{array}{l}\text { Higher support for E-Bikes to } \\
\text { encourage more diverse cyclist } \\
\text { pool }\end{array}$ & $\begin{array}{l}\text { Electric (4) } \\
\text { Scooter (2) }\end{array}$ & $\begin{array}{l}\text { 'E-bikes have the potential to overcome many } \\
\text { people's reluctance to cycle because of } \\
\text { perceived physical/fitness limitations. May } \\
\text { also assist with limits to EOT facilities'. }\end{array}$ \\
\hline
\end{tabular}




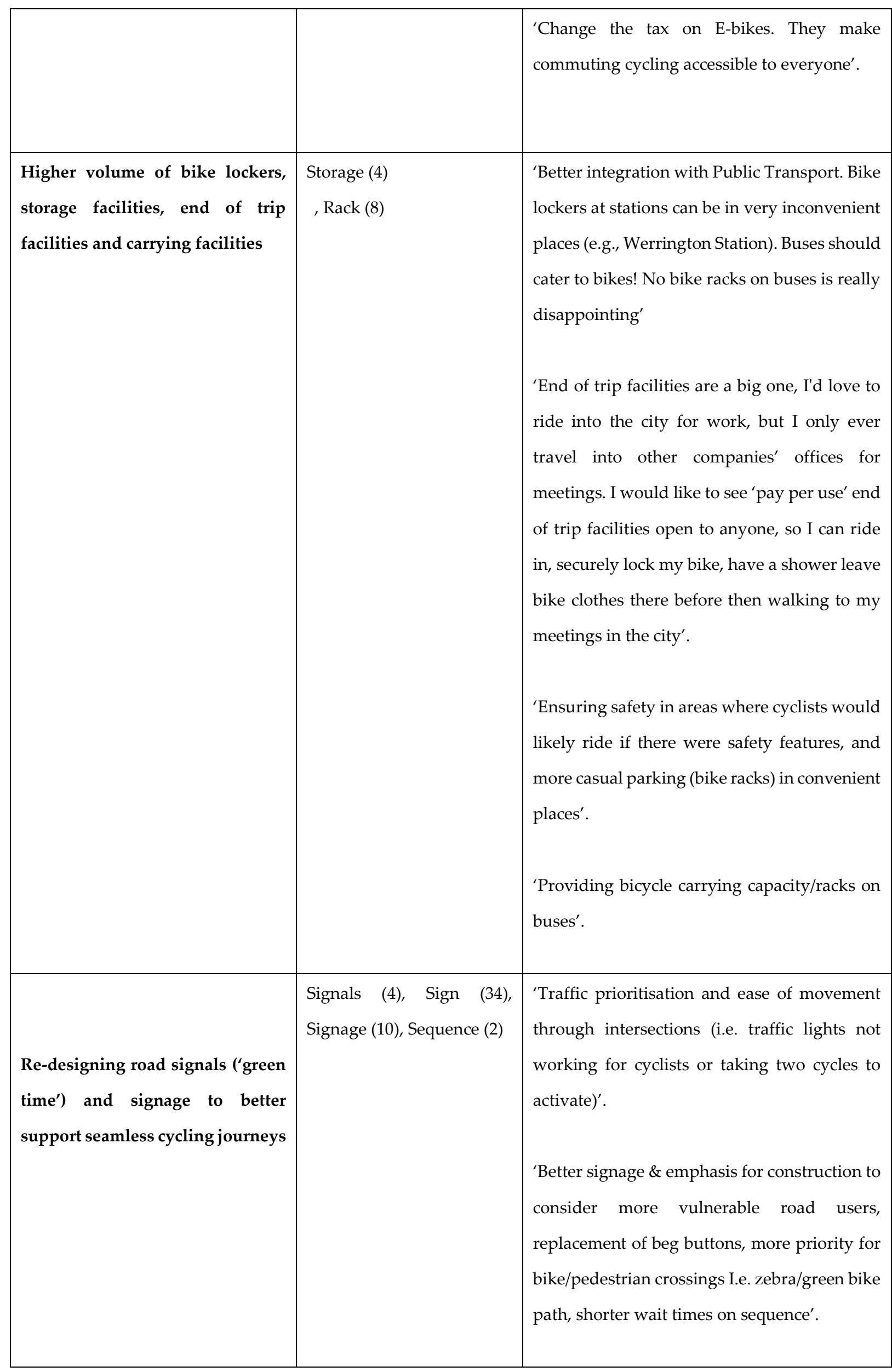


'Light prioritisation- active transport: light rail, cyclists and pedestrians should be given the priority at intersections in the city. As an example, travelling north on the Kent Street cycle way at the corner of key street, the cyclists get a green light for 3 seconds! In the morning it is impossible for the queue of bikes to get through'.

'Signage. And better apps. The rms map is ok but needs to be significantly more detailed. Google maps is ok but doesn't do a great job of finding the fastest cycleway route'.

'Still think there is not enough signage alerting motorists to be aware of cyclists - have never seen a sign advising motorists to be $1.5 \mathrm{~m}$ clear of a cyclist'. 


\section{Appendix 5}

Video describing prioritisation tool

The following media is also available to complement this research.
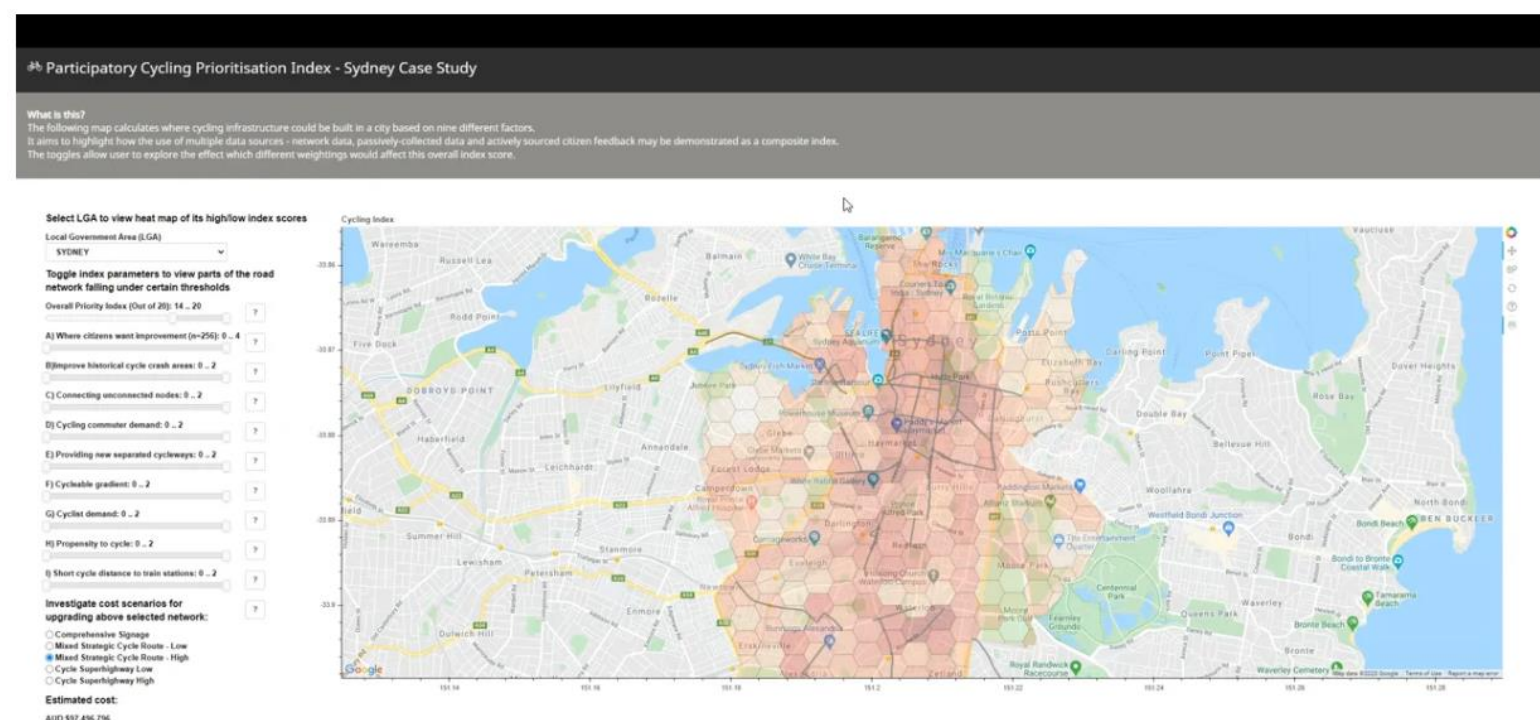

09:22

Link removed for peer review. Author details are included. 